Portland State University

PDXScholar

\title{
A Comparison of the Phonological Skills of Late Talking and Normal Toddlers
}

Patricia Joan Jennings

Portland State University

Follow this and additional works at: https://pdxscholar.library.pdx.edu/open_access_etds

Part of the Communication Commons, and the Phonetics and Phonology Commons Let us know how access to this document benefits you.

\section{Recommended Citation}

Jennings, Patricia Joan, "A Comparison of the Phonological Skills of Late Talking and Normal Toddlers" (1990). Dissertations and Theses. Paper 4082.

https://doi.org/10.15760/etd.5966

This Thesis is brought to you for free and open access. It has been accepted for inclusion in Dissertations and Theses by an authorized administrator of PDXScholar. Please contact us if we can make this document more accessible: pdxscholar@pdx.edu. 
AN ABSTRACT OF THE THESIS OF Patricia Joan Jennings for the Master of Science in Speech Communication presented April 4, 1990.

Title: A Comparison of the Phonological Skills of Late Talking and Normal Toddlers.

APPROVED BY THE MEMBERS OF THE THESIS COMMITTEE:

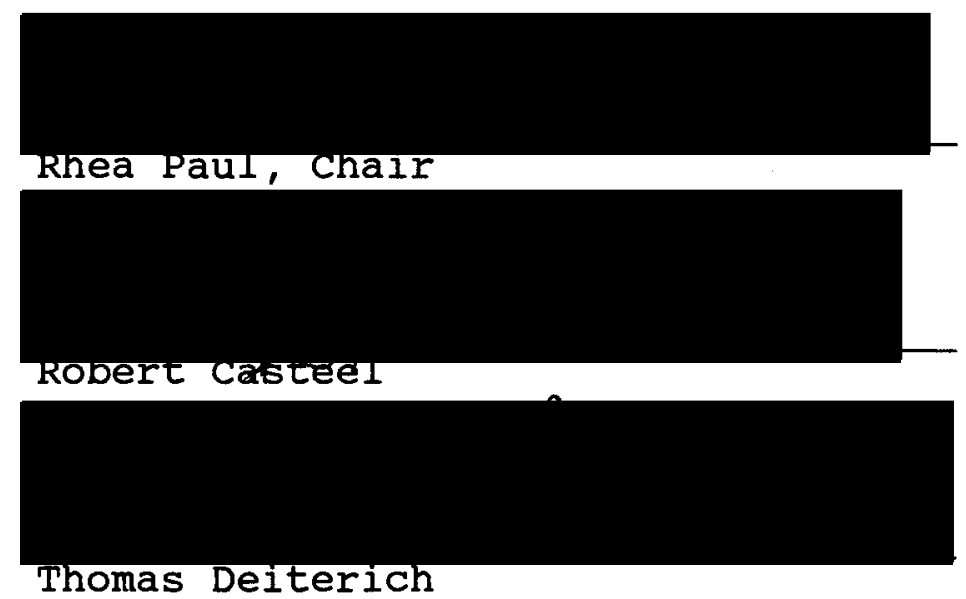

In the present study, the speech of twenty-four normally speaking toddlers and twenty-eight late talking toddlers was analyzed with respect to the syllable structures produced during a speech sample. The groups were matched with regard to age, sex, and socio-economic status, all passed a hearing screening, and all scored at least 85 on the Bayley Scales of Infant Development. 
Each child was videotaped interacting with his or her mother during a ten-minute play session. The subjects' utterances were broadly transcribed from these videotapes, using IPA symbols. Fifty consecutive different words or word-like utterances, or as many as could be transcribed out of the ten minute session, were coded from each subject. Each utterance was assigned to Syllable structure Level (SSL) I, II, or III, according to criteria designated by olswang et al. (1987), and a mean SSL was calculated. Inventories of consonant types were taken for each subject. In addition, each utterance was determined to be either meaningful or babbled. Meaningful utterances were glossed, and the percentage of consonants correctly produced was determined, for those subjects who produced at least ten meaningful words.

The data were analyzed for significant differences between the two groups in the mean SSL, number of consonant types, and percent consonants correct. Similarly, significant differences were sought between the older and younger sub groups within each group. The results indicated that children in this age group with normally developing expressive language have more advanced phonological development in terms of complexity of syllable structures, percent consonants correct in meaningful speech, and number of different consonant 
types produced, than do children who are late talking. The accuracy of phoneme production in children with normal language development improve over time, while that of LTs tends to remain relatively stable over the age range studied. Children with normal expressive language show less individual variation in phonological development than their late talking peers, and the individual variation decreases for the normal group as they get older, particularly after 25 months.

These data indicate that at least some children with expressive language disorders do have phonological delays. Therefore, the "general encoding deficit" described by Paul and Shriberg (1982) is supported here. 
A COMPARISON OF THE PHONOLOGICAL SKILLS OF LATE TALKING AND NORMAL TODDLERS

\author{
by \\ PATRICIA JOAN JENNINGS
}

A thesis submitted in partial fulfillment of the requirements for the degree of

\author{
MASTER OF SCIENCE \\ in \\ SPEECH COMMUNICATION
}

Portland state University
1990 
TO THE OFFICE OF GRADUATE STUDIES:

The members of the Committee approve the thesis of Patricia Joan Jennings presented April 4, 1990.

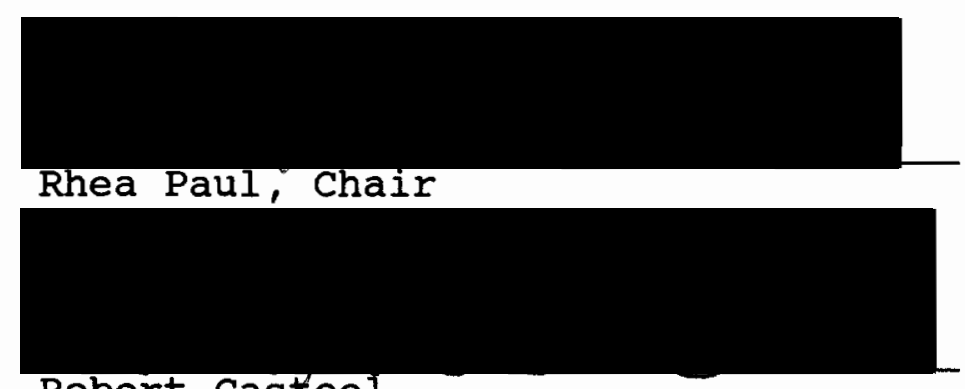

Robert Casteel

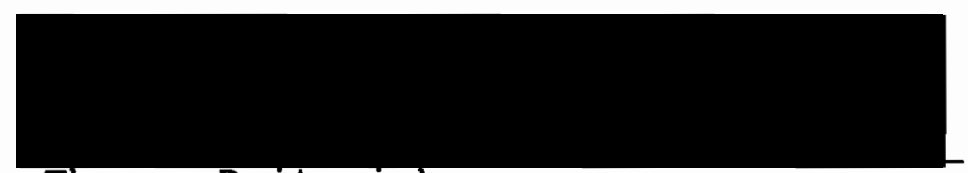

Thomas Deiterich

APPROVED :

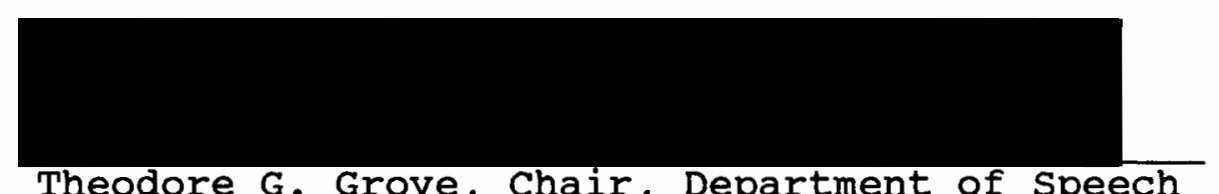

Theodore G. Grove, Chair, Department of Speech Communication

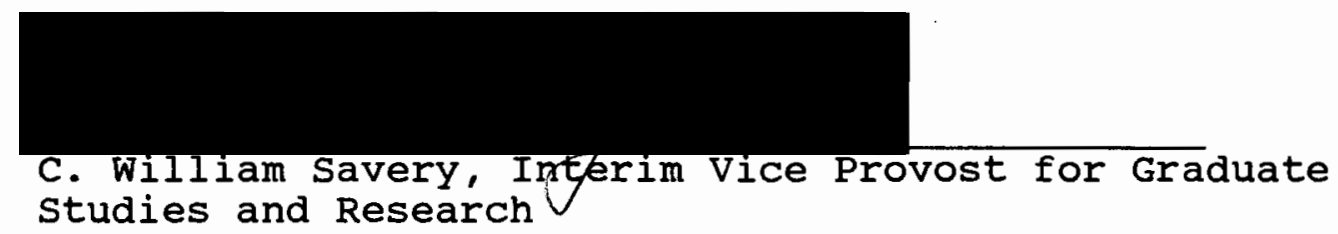




\section{ACKNOWLEDGEMENTS}

Thanks are due to many people for their parts in supporting me throughout the course of my involvement in this thesis. Before thanking them, however, I must first and above all thank God, because He has provided for all of my needs by providing these people, and by loving me unconditionally. He was my constant companion through long nights at the computer, late evenings in the library, repeated hearings of unintelligible videotapes, and high-speed chases to the University to beat deadlines.

Now, to the people who made this thesis possible. Dr. Rhea Paul, my thesis advisor, pushed me each step of the way and provided guidance and direction to the thesis. In addition to providing the videotapes of the subjects and their mothers, the shape, scope, and perspective of this thesis are based on recommendations she made. Randi Jartun, my reliability rater, spent many hours learning the transcription rules, asked innumerable enlightening questions, and did her best through some difficult times and working conditions, which included one grouchy trainer.

My parents, Lee and Gladys Jennings, provided for my 
needs, such as housing and food, while placing very few demands on me, and encouraged me. They also gave up a major portion of their living room and, at times, their whole house.

My brothers and sisters and their spouses, Bruce and Kelly Jennings, Sharon and Norm Bowler, Kent Jennings, and Ted and Nancy Vanzwol, encouraged me, put up with my moodiness and inaccessability, and provided moments of laughter when I let them. I would especially like to thank Bruce and Norm, who allowed me to use their company's computer and printer for the final draft of the thesis.

The staff and members of Columbia Presbyterian Church allowed me to use their video equipment for transcription of tapes, encouraged me, prayed for me, and counselled me. The choir especially was supportive. I think of them as my "cheerleaders"

I owe an enormous debt of gratitude to Richard and Janet Geary, who very generously provided many different kinds of support throughout my career in graduate school. Without them, my dream of completing my Masters degree would have been impossible. They are my "angels". 
TABLE OF CONTENTS

PAGE

ACKNOWLEDGEMENTS..................... ii

LIST OF TABLES........................ vii

LIST OF FIGURES...................... viii

CHAPTER

I INTRODUCTION................... 1

Introduction................ 1

Statement of Purpose............ 3

Null Hypotheses............... 3

Definition of Terms............ 4

II REVIEW OF THE LITERATURE........... 7

Areas of Child Phonology Studied..... 7

Theories of Transition

Aquisition of Phones

Phonological Processes

Studies of Two Year Olds

Interactions Between Phonology

and Language

Tentative Conclusions From Research... 28

Methodological Issues

III METHODS AND PROCEDURES............. 31

subjects.................. 31

Speech Sample Procedures......... 32 
Speech Sample coding............ 33

Reliability................. 36

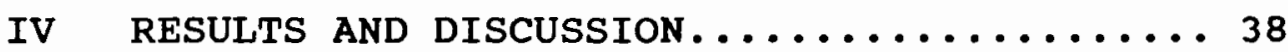

Results................... 38

Tests of Hypotheses Regarding

Sub-Groups

Group Differences

Observations

Discussion................. 51

v SUMMARY AND IMPLICATIONS........... 55

Summary..................... 55

Implications............... 58

Research Implications

Clinical Implications

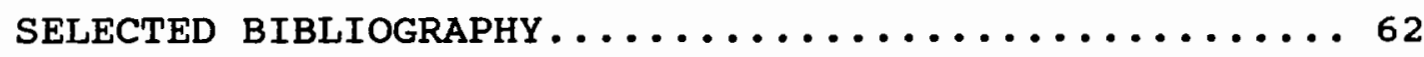
APPENDICES

A LETTER TO PARENTS AND QUESTIONNAIRE......6 68

B DEMOGRAPHIC DATA............... 71

C LETTER TO PARENTS AND CONSENT FORM....... 74

D CODING FORM.................. 76

E CODING INSTRUCTIONS............... 79

F SUBJECT DATA................. 82 


\section{LIST OF TABLES}

I Summary of Demographic Data............ 32

II Comparison of Ages, Number of Utterances, and Number of Repetitions per Utterance, by

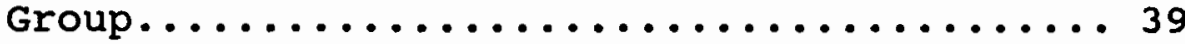

III Comparison of Mean Syllable structure Levels of the Normal and Late Talking subjects..........................40 40

IV Comparison of Mean Number of Different Consonant Types of the Normal and Late Talking subjects....................4 41

V Comparison of correct Consonants of the Normal and Late Talking Subjects Producing More than Ten Meaningful Words........... 42

VI Comparison of Mean Syllable structure Levels of the Younger and older Subjects, within Their Groups.................. 44

VII Comparison of Different Consonant Types of the Older and Younger Subjects, by Group.... 45

VIII Comparison of Correct Consonants of the older and Younger subjects, by Group....... 47

IX Comparison of Variances Between Sub-Groups.. 49

$X$ Ranges of Scores on Five Variables For the Older Normal and Late Talker Sub-Groups in a Ten-Minute Speech Sample, Up to Fifty Utterances................ 50 


\section{LIST OF FIGURES}

FIGURE

PAGE

1. Curves showing progress of developments of consonantal sounds in each of five major categories according to place of

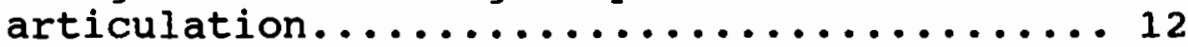

2. Curves showing relative proportions of consonant categories according to manner of articulation.......................13

3. Average age estimates and upper age limits of customary consonant production......... 15

4. Comparison of SICD with Sander's analysis of customary consonant production......... 16

5. Percentage of correct production of individual consonants based on total occurence of each phoneme...................... 17

6. Selection characteristics based on the syllabic structures of the adult words attempted.... 26 
CHAPTER I

INTRODUCTION

Phonology is the study of the rules by which speech sounds are selected and combined to produce the distinctive phonemes and syllables of a specific language. Only a fraction of the sounds which could possibly be produced by the human speech mechanism are actually used in any one language. The phonological system of the language determines which sounds, or "phones", are used, and in what distribution. The phones which are used distinctively in a language are called the "phonemes" of that language. In addition to phones and phonemes, the study of phonology includes observation of syllable structures produced by the speakers of a language. For example, in English, some of the syllable structures used are the following: Consonant-Vowel (CV), i.e., "bye"; CVCV, "baby"; Vc, "an"; CVC, "dad"; CCVC, "stop"; VCC, "and"; CVCC, "cups"; CVCCC, "costs"; CCVCC, "trips"; CCCVCC, "streets"; and CCCVCCC, "strengths".

While phonology is frequently used in comparing one language to another, the present study addresses the early childhood development of English phonology.

Children produce a variety of sounds in infancy, and around the end of the first year of life these sounds begin 
to be used meaningfully to refer to things in the child's world. While most children make this transition relatively smoothly and complete it by their second birthday, some do not. Paul and Shriberg (1982) describe a "general encoding deficit", which some of these late talking children might have. The encoding deficit model states that, in children whose speech is delayed, "children [with deficits] are generally limited in their capacity to manage hierarchical complexity during encoding. One result...is loss of phonetic accuracy due to competing demands for processing resources at higher linguistic levels." (p. 536).

Studies of phonological development in children have taken a variety of forms, including diary studies, studies of very small numbers of children, and studies of children well past the age of transition from babbling to speech. More recently, child phonological studies have focused on normal children making the transition from babbling into speech, as well as on the phonological characteristics of preschoolers with poor speech development. Few studies, though, have looked at phonological behavior in children with delayed language skills who are in the earliest stages of speech development. It has been shown (Paul and Shriberg, 1982) that there is a close association between speech and language development in preschoolers with communication disorders. At the present time, however, there are few data available to help in determining whether 
a toddler who is not talking is impaired primarily in a phonological or a semantic/syntactic dimension.

\section{STATEMENT OF PURPOSE}

The primary purpose of this study was to describe the phonological characteristics of toddlers with slow expressive language growth, and to contrast them to the phonology of vocalizations of normally speaking toddlers. This study addressed the following specific questions: 1.) Are there differences between the syllable structures produced by toddlers with normal language development and those produced by children with slow expressive language development?

Specifically, do the children with normal language produce more complicated syllable structures than those with delayed language?

2.) Do the children with slow expressive language development produce fewer different consonants and fewer correct target consonants than children with normal language growth?

3.) Is chronological age an explanatory factor in the phonological preformance of the two groups?

NULL HYPOTHESES

A. The mean Syllable structure Level (SSL) of the normal group is not significantly higher than the SSL of the 
delayed group.

B. The mean number of true consonants used by the normal group is not significantly higher than the mean number of true consonants used by the delayed group.

c. The mean percentage of consonants correctly produced by the normal group is not significantly higher than the mean percentage of consonants correctly produced by the delayed group.

D. The ssLs of the older subjects are not significantly higher than the ssLs of the younger subjects.

E. The number of true consonant types produced by the older subjects is not significantly higher than the number of true consonant types produced by younger subjects.

F. The percent correctly produced consonants of older subjects is not higher than that of younger subjects.

\section{DEFINITION OF TERMS}

The following operational definitions were used for the purposes of the present study.

1. Babbled Utterance. Any speech-like utterance the child produces which does not resemble any English word that might be expected in the context, and which is not credited with any specific meaning by the mother or the rater. This excludes crys, coughs, and screams, but includes any vocalization containing "a voiced vocalic element or a voiced 
syllabic consonant" (Olswang et al., 1987). Vocalizations produced on an ingressive airstream are also excluded.

2. Syllable Structure Levels. A complexity level (I, II, or III), is assigned to each babbled vocalization or meaningful utterance in a speech sample, depending on the distribution and type of consonants used within the vocalization (Olswang et al., 1987). See p. 35 for definitions of the three Syllable structure Levels.

3. Late Talkers (LTS). For the purposes of this study, children who are late talkers have, by parental report, an expressive vocabulary of fewer than 10 recognizable words at 18-23 months, or an expressive vocabulary of 50 words or less, or no two word combinations at 24-34 months.

4. Meaningful Utterance. Utterances which have obvious referents or clear communicative intent, and are phonemic approximations of the English words they are assumed to represent. In order for an utterance to be considered meaningful, the adult target word must be known.

5. Normal Language Development. In this study, this is defined in the following way: children who have expressive vocabularies of more than ten words at 18-23 months or expressive vocabularies of more than 50 words, and the use of some two word combinations at 24-34 months, by parent report.

6. Speech Sample. Speech samples in this study 
consist of broad phonetic transcriptions of up to fifty words or word-like utterances from the videotape of each child. On those tapes which have more than 60 such utterances, the first ten utterances were not coded. 8. Syllable structure. This term refers to the arrangement of vowels and consonants produced by a child in either babbled utterances or meaningful speech.

9. True Consonant. A true consonant is any consonant which is phonemic in adult American English speech. 
CHAPTER II

REVIEW OF THE LITERATURE

AREAS OF CHILD PHONOLOGY STUDIED

The transition from babbling to speech is extremely complex, and studies of the phenomenon have approached it from several different perspectives. Areas which have interested researchers include the phonological characteristics of babbled productions, acquisition of adult phonemes, phonological simplification processes in young children's speech, interactions between phonology and development of meaningful language, and, more recently, comparison of the speech of normal and late talking children. Methods employed in the study of babbling and early speech are also varied. Diary studies, in which a parent transcribes as many utterances as possible of his or her own child during the child's speech development period, have been used extensively. Some single-subject studies have sampled the utterances of one child regularly over a period of several months. Longitudinal studies of larger numbers of children, also over a period of several months, appear with some frequency. Cross-sectional studies, such as the present investigation, are less common. 
By far the most frequent focus of studies regarding early childhood phonology has been the acquisition of phones. However, some studies also describe other aspects of phonology, particularly prosodic elements such as pitch and intonation contours, phonological processes, and syllable structure.

\section{Theories of Transition}

Much of the research in the area of early phonological development has been in response to Jakobson's theory of child phonology, which included a universal order of the acquisition of speech sounds and a "silent period" between babbling and speech (Jackobson, 1968). Jakobson's work, originally published in 1941 in German, seems to have been widely accepted by linguists and speech pathologists alike, until the 1970's. Because of this, most of the research on this topic has been conducted within the past twenty years. Scientific investigation relatively quickly produced extensive evidence refuting Jakobson's theory. Diary studies of were the primary means of investigating developmental phonology at that time. If one, otherwise normal, child acquired phonemes differently than what was assumed to be the norm, the theory of universal principles was weakened considerably.

Diary studies, usually conducted by the parents of the subjects, begin when the subject produces his or her first recognizable word and end when the child's expressive 
vocabulary is too large to count. Normal, often superior, children, are nearly always the subjects of these studies. These children did not, in fact, follow the "universal order" of phoneme acquisition. (Smith, 1973; French, 1989). Data collected in diary studies includes information regarding syntactic, semantic, and other aspects of language development, as well as phonological inventories. The data from various diary studies has been published, so researchers can analyze it according to other theories and compare the subjects with other children. Transcriptions of babbled utterances are not included, however, and thus the data cannot be compared directly to data from the present study. Edwards and Shriberg (1983) discuss four of these studies, noting that the emphasis in the area of articulation is on the acquisition of segments, or phones, rather than on phonological processes or on syllable structure.

In contrast to Jakobson's "nativist" theory, the behaviorist theory of phonological acquisition was based on the principle that sounds which children produce correctly are reinforced by adults (Menn, 1985). It was expected that those sounds which were used most frequently would be the quickest to develop, as they would be reinforced most often. As with Jakobson's theory, the behaviorist theory did not hold up well under scientific scrutiny. Review of diary studies and cross sectional studies indicates that the 
most frequently used sounds are not necessarily the first to be mastered. (Sanders, 1972; Irwin, 1947a, 1947b, for example.) In fact, one of the most frequent sounds of the English language, $/ \mathrm{s} /$, is one of the last sounds to be mastered by many children. In addition, many children are observed to regress in their phoneme acquisition, i.e., they seem to have mastered a phoneme early in their speech development, but go through a later period during which the same phoneme is not used, or is used inconsistently. (Menn, 1985).

No one theory has yet fully explained the various phenomena observed in phonological development, although trends in the acquisition of phonemes are seen in the data (Menyuk, Menn, and Silber, 1986.) Children seem to choose structures for production which fit into their own developing overall phonological systems (Ferguson and Farwell, 1975), and early speech follows phonological patterns established in the late babbling period (Vihman and Greenlee, 1987). The task researchers face, then, is to describe the phonological development of individuals and groups of children, hoping analysis of the data can reveal patterns which will increase understanding of this complex process. 


\section{Acquisition of phones}

Several studies, which have involved large populations of children, have been conducted in order to establish norms for the acquisition of phonemes. Irwin, (1947a, 1947b, 1948) conducted the earliest of these studies, in which the development of phonemes from the age of 0.0 to 2.6 is described. Irwin included more than 50 subjects at each two month age level. Inventories of consonants and vowels were taken from transcriptions of thirty exhalations in each session. While the ages of the subjects were similar to those of the present subjects, no differentiation was made between normal and late talkers, and the utterances transcribed were not glossed. Therefore, no analysis of the number of correct phonemes was possible. Also, syllable structures were not noted. For each age group, Irwin determined the percentage of phonemes produced, according to place and manner of articulation. Regarding place of articulation, children younger than one year are described as producing primarily glottal sounds, while velar, labial and labio-dental, and "post-dental" all are produced at rates of less than $30 \%$. At about one year, the percentage of glottal sounds decreases significantly, while the rate of post-dental and labial and labio-dental sounds increases significantly. These trends continue until approximately two years, when the rates stabilize. The speech productions 
of children at age 2.6 are described as having nearly the same distribution of phonemes as adult speech. Regarding manner of articulation, plosives and fricatives are the most common types produced, while nasals, glides and semi-vowels are produced at much lower rates throughout the period studied. The rate of plosives drops sharply between two months and eight months, then increases sharply and stabilizes at 45-50\% from the age of 1.0 through the end of the period. Fricatives generally decrease steadily from 6 months through 22 months, stabilizing at approximately $20 \%$. The results of these studies are summarized in Figures 1 and 2 .

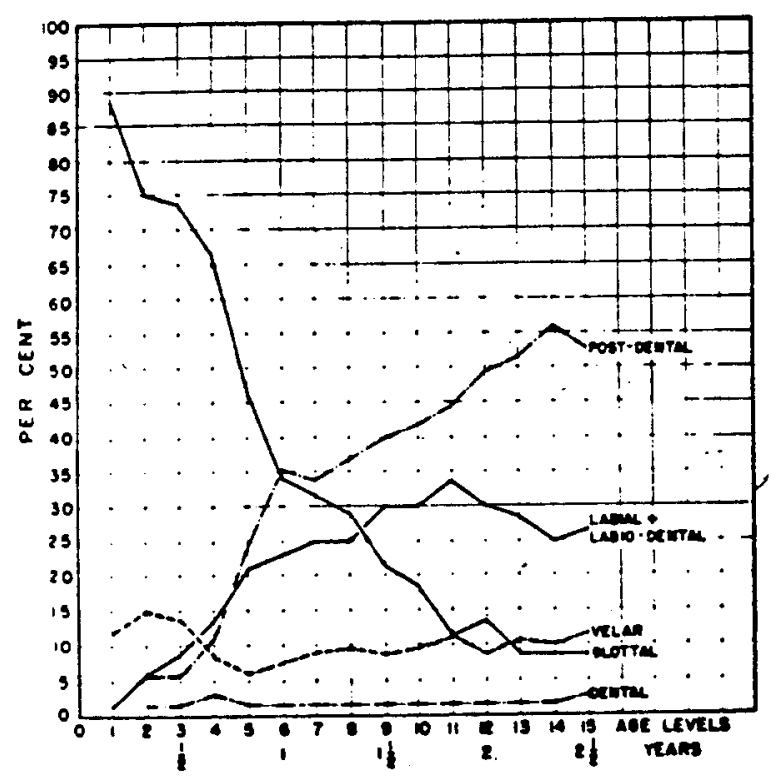

Figure 1. Curves showing progress of developments of consonantal sounds in each of five major categories according to place of articulation. Reproduced from Irwin, 1947a, p. 399. 


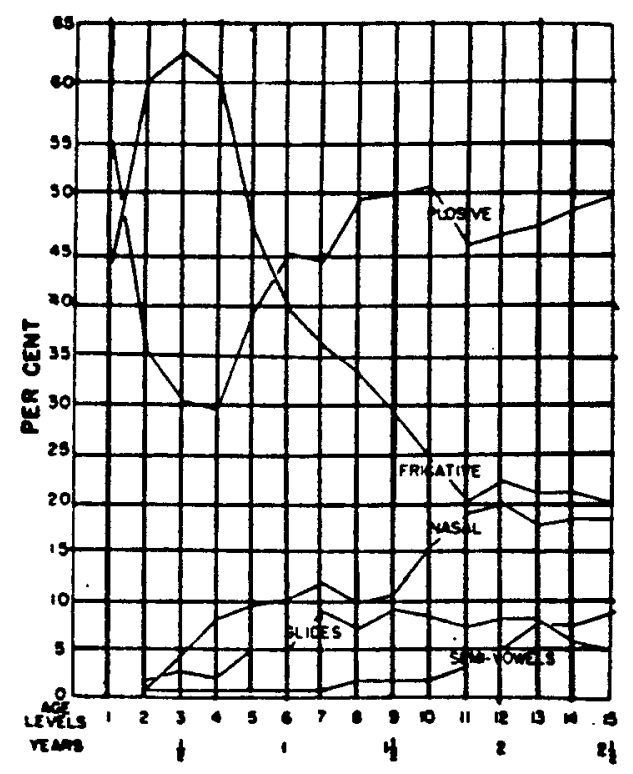

Figure 2. Curves showing relative proportions of consonant categories according to manner of articulation. Reproduced from Irwin, 1947b, p. 404 .

Sanders (1972) combined the results of two studies (Templin, 1957, and Wellman, Case, Mengert, and Bradbury, 1931). From these, Sanders developed the chart reproduced in Figure 3.

More recently, researchers have attempted to describe acquisiton of phonemes among groups of children in certain age ranges. These include Prather, Hedrick, and Kern (1975), two to four year olds; Paschall (1983) 18 month olds; Hare (1983), two year olds; Larkins (1983), three year olds; Stoel-Gammon (1987), two year olds; and Dyson (1988), two year olds. The subjects of all of these studies were children whose speech and language were considered to be developing normally. 
Prather, et al. (1975) revised Sander's chart of phoneme acquisition, as can be seen in Figure 4, by including data obtained by testing additional children at younger ages.

Paschall (1983), Hare (1983) and Larkins (1983) all applied the same analysis procedures to samples of the spontaneous speech of children. This analysis included distribution of phonemes, percentage of correct production of consonants, error type distributions, and various analyses based on the Irwin-Wong distinctive features system and the Chomsky-Halle distinctive features system. All three authors state that their data indicate earlier acquisition of phonemes than had been reported in previous studies, based on percentage of correct production of consonants. The eighteen month olds are reported to produce 50\% of consonants correctly; the two year olds, 63\%; and the three year olds, 93\%. Because this is analysed by phoneme, it can be seen which phonemes are produced with the most accuracy at each age. The distribution of phonemes analysis results are shown in Figure 5 .

In an effort to provide a more reliable account of the phonological acquisition of children at the age of 24 months than is given by Sanders or Prather et al., Stoel-Gammon (1987) conducted a study of 33 normally developing children at this age. Based on speech samples, rather than test items, the data was analysed with regard to word-initial and 


\section{AGE LEVEL}

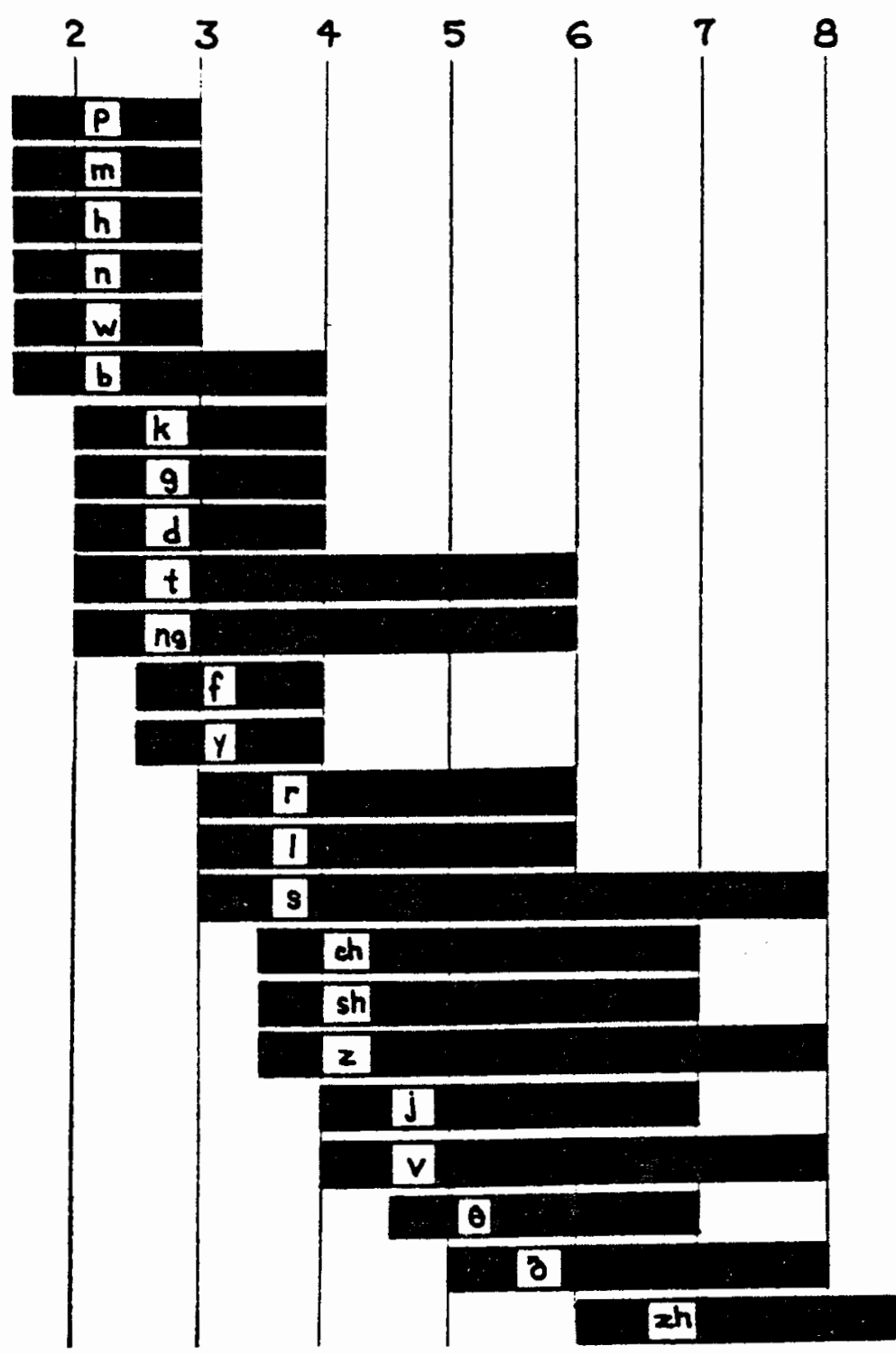

Figure 3. Average age estimates and upper age limits of customary consonant production. The solid bar corresponding to each sound starts at the mendian age of customary articulation; it stops at an age level at which $90 \%$ of all children are customarily producing the sound. Reproduced from Sanders, 1972 , p. 62. 


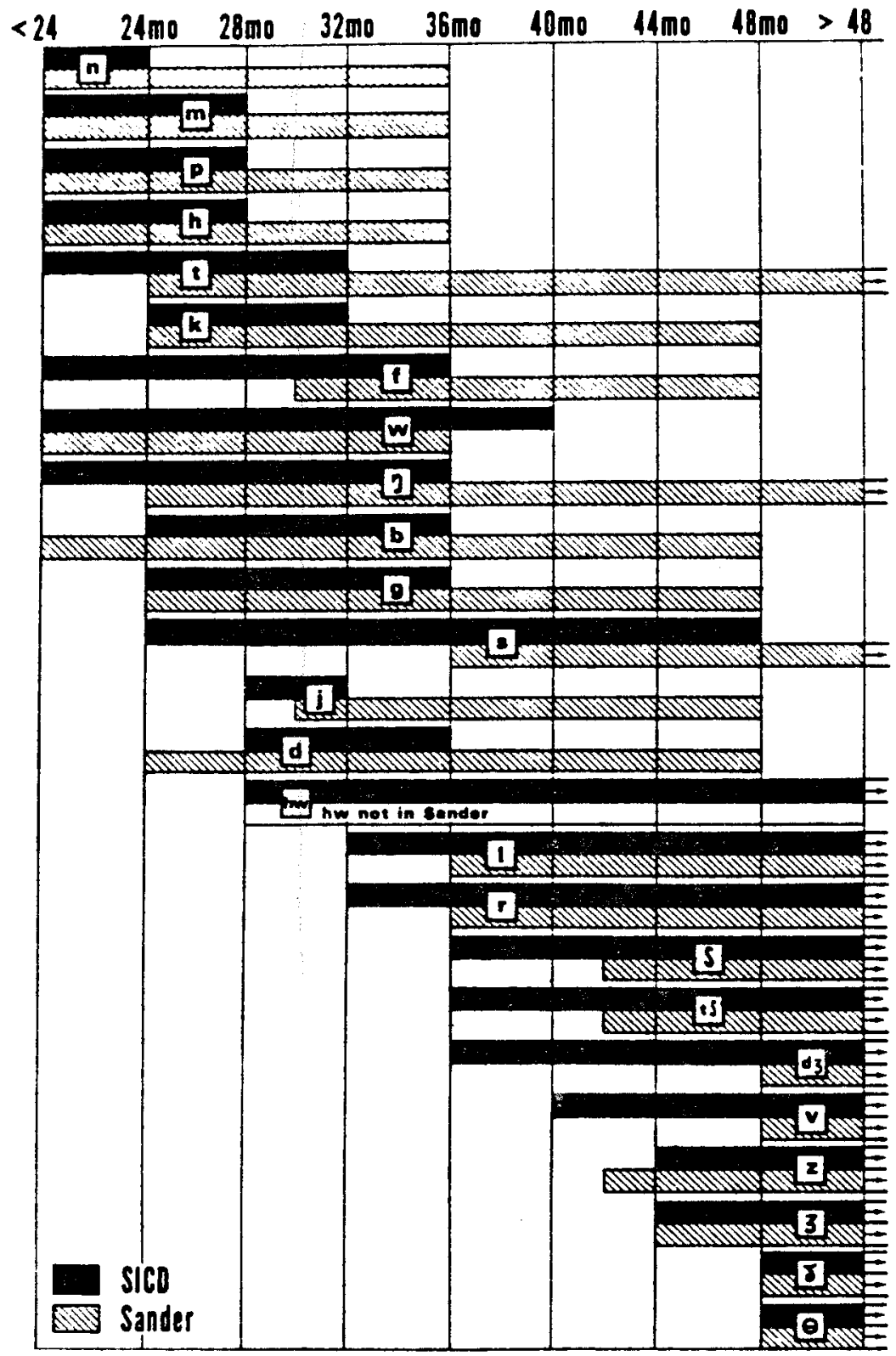

Figure 4. Comparison of SICD with Sander's (1972, p. 62) analysis of customary consonant production. When the percentage correct at 24 months exceeded $70 \%$, the bar extends to the left $<24$. When the $90 \%$ level was not reached by 48 months, the bar extends to the right $>48$. Reprinted from Prather, et al., 1975, p. 181. 


\begin{tabular}{|c|c|c|}
\hline Phoneme & $\begin{array}{l}\% \text { Correct } \\
\text { Production }\end{array}$ & $\begin{array}{l}\text { No. of Correct Occurrences/ } \\
\text { No. of Total Occurrences }\end{array}$ \\
\hline /b/ & 90 & $1,238 / 1,370$ \\
\hline$/ \mathrm{m}$ & 84 & $438 / 524$ \\
\hline$/ \mathrm{j} /$ & 71 & $12 / 17$ \\
\hline$/ \mathrm{h}$ & 68 & $168 / 247$ \\
\hline /f $/$ & 67 & $95 / 142$ \\
\hline$/ d /$ & 63 & $355 / 567$ \\
\hline$/ \mathbf{n} /$ & 63 & $235 / 375$ \\
\hline$/ w /$ & 63 & $50 / 79$ \\
\hline$/ \mathbf{p} /$ & 56 & $228 / 409$ \\
\hline $\mid g /$ & 49 & $141 / 289$ \\
\hline$/ \mathbf{k}$ & 47 & $403 / 865$ \\
\hline$/ \mathrm{t}$ & 36 & $217 / 609$ \\
\hline$/ \mathrm{t} s /$ & 22 & $21 / 96$ \\
\hline$i \mathbf{v} /$ & 13 & $5 / 40$ \\
\hline$/ d_{3} /$ & 9 & $5 / 58$ \\
\hline $\mid \mathbf{s}$ & 8 & $27 / 333$ \\
\hline $18 /$ & 5 & $4 / 75$ \\
\hline IV & 4 & $19 / 452$ \\
\hline$/ g /$ & 3 & $3 / 94$ \\
\hline is/ & 2 & $2 / 106$ \\
\hline$|\boldsymbol{T}|$ & 2 & $6 / 329$ \\
\hline$/ z$ & 1 & $2 / 138$ \\
\hline$\theta$ & 0 & $0 / 113$ \\
\hline 3 & 0 & $0 / 0$ \\
\hline$D$ & 0 & $0 / 0$ \\
\hline Total & 50 & $3.674 / 7.327$ \\
\hline
\end{tabular}

Figure 5. Percentage of correct production of individual consonants based on total occurrence of each phoneme. Reprinted from Paschall, 1983.

word-final consonant inventories, syllable types, and percentage of consonants produced correctly. A profile of the "typical two year old's" phonological skills was developed, as follows.

He or she can:

1. produce words of the form CV, CVC, CVCV, and CVCVC;

2. produce a few consonant clusters in initial position and maybe one or two in final position;

3. produce 9-10 different consonantal phones in initial position, including exemplars from the classes of stops, nasals, fricatives, and glided;

4. produce 5-6 different consonantal phones in 
final postion, mostly stops but also a representative from the nasal fricative, and liquid sound classes:

5. match the consonant phonemes of the adult word at a level of $70 \%$ correct. (StoelGammon, 1987, p. 327-328.)

Dyson (1988) studied the word-initial and word-final consonant production of two groups of ten children at 2.0 , $2.5,2.9$, and 3.3 years. The results of this study were consistent with other studies of the same phenomena in younger and older children. Specifically, while previous reports had listed word-initial inventories as including "voiced anterior stops, nasals and glides," with velars and voiceless fricatives emerging by 24 months, Dyson noted that her somewhat older subjects also produced $/ p /, / 1 /$, and $/ j /$, and other palatals, which had been missing from younger subjects' consonant inventories (Stoel-Gammon, 1985). In addition, in the final position, $/ \mathrm{m} /, / \mathrm{n} /$ voiced stops, $/ \mathrm{s} /$, $/ \mathrm{v} /, / \mathrm{z} /$, and $/ \mathrm{S} /$ are emerging. Voiceless affricates appear, as do consonant clusters. The most common syllable type reported in this study is $\mathrm{CVC}$, followed by $\mathrm{CV}$ in the first three observations, and "combined other monosyllables" in the fourth.

\section{Phonological Processes}

Acknowledgment of the role of phonological simplification processes has had an effect on the way in which phonology is investigated. Recent studies (Hodson and Paden, 1981; Dyson and Paden, 1983; and Preisser, Hodson and 
Paden 1988, for example) have focused not on the aquisition of individual phones, but on the kinds of errors children make, such as deletion of final consonants or reduplication of syllables. Most studies in this area have been conducted using very small samples, and many studies of developmental phonology focus on children who are three years old or older (i.e., Campbel1, 1982; Hodson and Paden, 1981.) In these studies, much individual variation is noted in all aspects of phonological development.

A major work using diary studies to make conclusions regarding syllable structure acquisition is Ingram (1976). Ingram surveyed accounts of four children's first 50 words and analyzed their phonology. In the sample, the childrens' first syllables were Consonant-Vowel (CV), for example, /da/ for "dog"; or CVCV, reduplicated, (/baba/ for "bottle"). VC syllables ("up") also occured, and there were some occurances of $\operatorname{CVC}\left(/ \mathrm{b}^{\wedge} \mathrm{k} /\right.$, "book"). Common syllable-related phonological processes at this age, as reported by Ingram, include final consonant deletion (usually lost between ages 1-6 and 3-0), which results in $\mathrm{CV}$ or $\mathrm{V}$ syllables, for example "out" becomes /au/: reduplication; deletion of unstressed syllables ("potato" becomes /teto/); and cluster reduction ("stop" becomes /tap/). Additional data seem to indicate that Ingram's observations regarding syllable structure development were accurate (Stoel-Gammon and Dunn, $1985)$. 
Hodson and Paden (1981) compared the phonology of "essentially unintelligible" children, 3 to 8 years old, with that of normal, intelligible, four year olds. The researchers concluded that the phonological processes which identified the unintelligible children were cluster reduction, stridency deletion, and stopping, as well as final consonant deletion, fronting of velars, backing, syllable reduction, prevocalic voicing and glottal replacement.

\section{Studies of Two Year olds}

Recently, some researchers have begun investigating the speech productions of two year olds, focusing on syllable structure development and other aspects of phonology. The first such study was conducted by Smith (1973). In this diary study, the subject's utterances from the age of two years, 60 days through 3 years, 355 days were thoroughly analysed regarding all aspects of phonology. The results of this study are extremely complex, and are primarily of theoretical interest, rather than clinical. Smith describes 26 rules his son applied to English Standard Pronunciation and how the application of the rules changed over time. From this empirical data, he draws five theoretical conclusions, the second and third of which are of interest to the present researcher. The second conclusion is that "the child's phonological development is rule-governed and 
all changes in his output over time are the result of changes in rules applying to phonologically (and grammatically) defined classes." (p. 206). In the third conclusion, Smith suggests four "hierarchically arranged universal tendencies: 1) vowel and consonant harmonization, 2) cluster reduction leading to a CVCV...canonical form. 3) systematic simplification 4) grammatical simplification." (p. 206).

Macken's (1979) single subject study of a child learning Spanish was important because of Macken's observation that "certain phenomena could best be accounted for by assuming a central role for the 'word' as the basic unit being acquired", rather than the phoneme or the syllable. After the age of 26 months, however, traditional phonological rules could be used to analyze the subject's phonological system. The "phenomena" mentioned were the use of idiosyncratic forms and the inconsistent use of simplification processes.

Dyson and Paden, (1983) and Preisser, Hodson and Paden (1988), discuss two year old phonology, with regard to the reduction of the use of phonological processes over time. In general, a substantial reduction in the use of phonological processes was noted during the third year, especially in velar fronting, stopping, and final consonant deletion. The processes of gliding and cluster reduction were also reduced, but remained in frequent use into the 
fourth year. These latter two were also the most frequently noted processes.

In a cross-sectional study, Vihman, Ferguson, and Elbert (1986) found that phonological processes in three and four year olds are rooted in the prelinguistic period. Children's first words are produced with phonological structures which are similar to their babbling phonology. As language development progresses, phonological processes imposed by the babbling structures are decreased, and production gradually becomes more like adult speech. They also note a wide range of individual variation in the phonologies of their ten subjects.

In a different study, Vihman (1987) found that the choice of sounds at age one, (some children choose more stop consonants and others choose more fricatives, for example,) does not predict mastery of those sounds at age three. However, she also found that a high use of babble containing true consonants at age one is predictive of greater phonological advancement at age three.

Gill (1987) studied the phonological development of a "language disordered" child from the age of 20 months through 32 months. Comparing the productions of this child with those reported in the literature, Gill recommends that consonantal inventories in conjuction with phonological process analysis be used as a diagnostic tool, and that phonological process application ratios be used as a measure 
of progress in phonological development. Gill also notes the need for additional longitudinal data on normal and language disordered populations, which should provide norming data for phonological processes.

Stoel-Gammon (1989) reports, in a study of two late talkers, that "atypical babbling may be associated with delays in the acquisition of meaningful speech." (p. 207).

\section{Interactions Between Phonology and Language}

Three studies (Ferguson and Farwell, 1975; Shibamoto and Olmsted, 1978; and Stoel-Gammon and Cooper, 1984) have examined the relationship between lexical and phonological development in children whose productive vocabularies included about 50 words. These researchers were interested in whether or not the children's phonologies influenced their selection of lexical items, the amount of individual variation in phonological output, and the order or pattern of acquisiton of speech sounds. Each of the researchers found distinct phonological patterns within the speech of the individual subjects, such as the use of primarily open sylables or the use of syllable reduplication, and some of the children used the same patterns, for example, two of Shibamoto and Olmsted's subjects used the process of fronting velars. Regarding lexical selection, it was found that several factors in addition to phonological ability are influential, although the child's ability to approximate the 
first phoneme of the adult word may be of some influence. Ferguson and Stoel-Gammon both noted great individual variation among their subjects. Stoel-Gammon states that this is true especially after the transition has been made from primarily babbled to primarily meaningful productions. Probably because of the individual variation, none of these researchers proposed a general order of phoneme acquisition, nor did they propose universal rules for development of phonological structures, although they all seem to indicate that such universals might be discovered by thorough analysis of additional data.

Studies of phonological development in language delayed children have been largely confined to children over the age of three, for example, Paul and Shriberg (1982). Paul and Shriberg identified four patterns of association between phonology and syntax, based on the utterances of unintelligible children over the age of three. The question addressed was whether the children's phonological disability influenced their syntactic ability. Every subject was determined to fall into one of the following patterns:

Pattern I: (30\%) The subjects display both syntactic and phonological deficits, with the phonology having a detrimental effect on production of complex morphophonemes. Pattern II: (20\%) The subjects' syntactic skills are normal, but their phonological skills influence the production of complex morphophonemes, which they otherwise 
might produce.

Pattern III: (36\%) The subjects syntactic and phonological skills are both disordered, but the phonological deficit has limited influence on complex morphophonemes.

Pattern IV: (14\%) The subjects' syntactic skills are normal, and their phonological skills have no influence on production of complex morphophonemes.

Paul and Shriberg note that children who fall into Patterns I and II (50\%, in their study) provide evidence for a "limited encoding capacity model", in which lack of intelligibility is one symptom of a deficit in both phonological and syntactic production. In contrast, the remaining $50 \%$ of Paul and Shriberg's subjects' phonological disorders had little or no bearing on their syntactic output.

Studies contrasting the phonologies of language delayed and normal children under the age of three are not found in the literature. The subject of French's (1989) diary study was considered a "late talker" by the researcher, however, French noted that the subject's speech and language skills were normal by age 2.7 .

The effects of individual variation in language development on phonological development has been investigated by Schwartz, Leonard, Folger, and Wilcox, (1980). The subjects of the study were three normally developing children and three language disordered children, 
matched on the basis of MLU, which meant that the language disordered children were older than the normals. Based on language samples from these six children, Schwartz concluded that the phonological structures of the normal and the disordered children were more alike than different. See Figures 6 and 7 for examples of the findings of this study with regard to syllable structure selection and production.

\begin{tabular}{|c|c|}
\hline \multicolumn{2}{|c|}{ Syllabic Structures } \\
\hline Normal-Speaking & Language Disordered \\
\hline CVCVr (3) & CVCVr (3) \\
\hline CV (3) & $\mathrm{CV}(3)$ \\
\hline CVCVnr (2) & CVCVnr (2) \\
\hline $\operatorname{CVC}(3)^{* * *}$ & $\operatorname{CVC}(3)^{* * *}$ \\
\hline CVCVC (2) & \\
\hline $\operatorname{CVCC}(3)$ & CVCC (2) \\
\hline $\operatorname{CCVC}(2)$ & $\operatorname{ccvc}(1)$ \\
\hline VC (1) & VC (2) \\
\hline
\end{tabular}

Figure 6. Selection characteristics based on the syllabic structures of the adult words attempted. The number of children for whom the structure was productive is given in parentheses. Each asterisk indicates that this was the most frequent structure for one child. Reprinted from Schwartz, et al., 1980, p. 365 . 


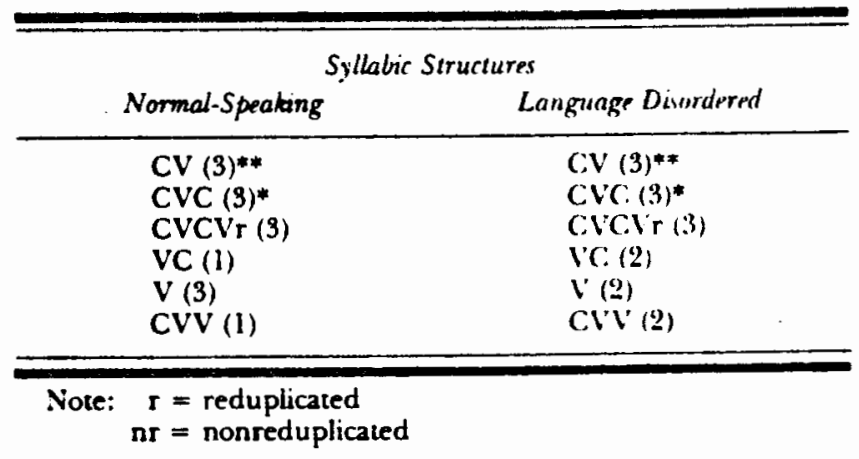

Figure 7. Production characteristics based on the syllabic structures of the children's productions. The number of children for whom the structure was productive is given in parentheses. Each asterisk indicates that this was the most frequent structure for a child. Reprinted from Schwartz, et al., 1980, p. 367 .

Matthei (1989), in a single subject study, analysed the phonological processes involved in early multi-word utterances, and found simplification processes similar to those noted elsewhere in single-word utterances. 
TENTATIVE CONCLUSIONS FROM RESEARCH

From the Nativist theory of Jacobson, child phonology theory has evolved to the point at which no theory seems adequate to explain the complex process of speech acquisition. While certain patterns may be followed, each child adopts his own style of learning speech and language. In the end, a theory of phonological acquisition will be required to account for both patterns and individual variation, a feat which no theory has yet accomplished.

While charts of the development of speech sounds have been developed, they should be considered guidelines, at best. Because of the small numbers of subjects on which they are based, especially at the two year old level, and because of the high degree of variability in rate of speech development, their reliability is inadequate to use them as a diagnostic tool. However, based on the research, normal two year olds should be expected to:

...produce 9-10 different consonantal phones in initial position, including exemplars from the classes of stops, nasals, fricatives, and glided; produce 5-6 different consonantal phones in final postion, mostly stops but also a representative from the nasal fricative, and liquid sound classes; match the consonant phonemes of the adult word at a level of $70 \%$ correct." (Stoel-Gammon, 1987, p. 327-328).

Gill recommends consonant inventories, in conjunction with phonological process analysis, be used as criteria for 
two year old phonological productions, although specific criteria levels are not given.

studies of phonological simplification processes indicate that unintelligible children over the age of three use several processes which are also used by normally developing children at the age of two. By the age of four, the normally developing child may still use stridency deletion, liquid simplification, and cluster reduction, stopping, and assimilation, but most other phonological processes should no longer be in use, and the child should be intelligible most of the time.

Very few studies have been conducted with very young children regarding the interaction between phonology and language, and those which have been done have focused on the issue of phonological influence on lexical selection. From these studies, few definite conclusions can be drawn, but it does appear that syntactic and phonological delays frequently co-occur. (Paul and Shriberg, 1982).

\section{Methodological Issues}

The criteria used to identify the late talking and normal subjects for the present study were based on the Language Development Survey (LDS) (Rescorla,1989). The LDS is a checklist of 300 of the most common words in early vocabularies and has been shown to have excellent reliability, validity, sensitivity, and specificity for 
differentiating normal two year olds from those with expressive language delays. In addition, Dale, Bates, Reznick, and Morrissett, (1989) and Reznick and Goldsmith, (1989) have shown that checklist formats are valid indices of expressive vocabulary style.

Several procedures have been developed which can be used to analyze children's phonological development. The procedure chosen to be used for the present study is the Language Production Scale (Olswang, Stoel-Gammon, Coggins, and Carpenter, 1987), primarily because this is the only tool available which can measure phonology of both babbled and meaningful speech. In conjunction with the development of this procedure olswang et al. performed studies to develop normative data. In these studies, they found that babbled utterances increased in complexity between the ages of nine and 18 months, and that fewer children were in the babbling stage by 18 months than at 9 months. They also note that, at 12 months, none of their 34 subjects was in the meaningful speech stage, but at 24 months, all subjects were using primarily meaningful speech. In addition, the percent of consonants correct in meaningful speech increased between the ages of 15 and 24 months. 


\title{
METHODS AND PROCEDURES
}

\author{
SUBJECTS
}

This study is part of a larger study of characteristics and outcomes of toddlers who are late talkers (LTS). The subjects were recruited from Portland area pediatric clinics and media advertisements. Criteria for inclusion in the LT group were: 1) production of less than ten words at 16-23 months, or, 2) production of less than 50 words and no twoword combinations at 24-34 months, by parent report. Expressive vocabulary size was determined by having parents select the words their child produced from the Language Development Survey (LDS) (Rescorla, 1989).

Children whose expressive vocabulary met the above criteria were invited to participate in a larger longitudinal study. Those whose expressive vocabularies exceeded the above criteria on the LDS were invited to join the normal group. The two groups were matched by age, sex ratio, and SES. Twenty-four children from the normal group and twenty-eight from the LT group served as subjects for the present study. The mean age of the normal group was $25.33 \pm 4.90$ months. The mean age of the late talker group 
was $24.93 \pm 3.99$ months. Table I reports demographic data on the subjects involved in this investigation. All subjects in the study passed hearing screening by means of visually reinforced audiometry at $20 \mathrm{~dB}$. The Bayley scale of Infant Mental Development (Bayley, 1969) was administered to each subject by a trained psychologist, and no subject in either group scored lower than 80 on the Mental Development Index (MDI) of the Bayley. AlI subjects were also screened informally by observation for signs of autism, crainofacial or neuromotor dysfunction (Paul and Shiffer, 1987).

\section{TABLE I}

SUMMARY OF DEMOGRAPHIC DATA

(FROM SHIFFER, 1988)

\begin{tabular}{lcccc} 
Group & $\begin{array}{c}\text { Mean Age } \\
\text { in Months }\end{array}$ & SES & Race & Sex \\
Normal & 25.33 & $2.48 *$ & $\begin{array}{l}88 \% \text { White } \\
12 \% \text { Minority }\end{array}$ & $\begin{array}{l}71 \% \text { Male } \\
29 \% \text { Female }\end{array}$ \\
$\begin{array}{l}\text { Late } \\
\text { Talker }\end{array}$ & 24.93 & $2.89 *$ & $\begin{array}{l}89 \% \text { White } \\
11 \% \text { Minority } 36 \% \text { Female }\end{array}$ & $\begin{array}{l}64 \% \text { Male } \\
36 \%\end{array}$ \\
\hline & $\begin{array}{l}\text { *Based on Hollingshead's scale of 1 to 5 with 1 } \\
\text { being the highest socio-economic status and 5 } \\
\text { being the lowest. (Myers and Bean, 1965) }\end{array}$
\end{tabular}

SPEECH SAMPLE PROCEDURES

Each subject was videotaped interacting with his or her mother in a small classroom for approximately ten minutes. Mother and child were both seated on a carpeted area, and each mother was instructed, "Please play with your child as you normally would at home. I will be videotaping you for 
ten minutes." The same high-interest toys were used with each child, so that a somewhat uniform vocabulary might be elicited. Toys included Disney Poppin' pals, dolls, dishes, a telephone, stacking rings, cars, a xylophone, blocks, and a wratchet-shape toy.

The videotaping was done by two graduate students, using a Panasonic Vicon WV-3150 video camera and an Electrovoice professional dynamic microphone, in conjunction with a Panasonic NV 8200 video cassette recorder.

\section{SPEECH SAMPLE CODING}

The researcher obtained the data for the present study by tanscribing the utterances the children produced on the videotapes. During the transcription process, the researcher was blind to the subjects' diagnostic group assignment. Speech samples were transcribed according to procedures described in the Language Production scale (LPS), (Olswang et al, 1987). Speech samples of 50 consecutive different words or word-like utterances from each subject were broadly transcribed using International Phonetic Alphabet (IPA) symbols, as is prescribed for the Language Production Scale (LPS). Exact repetitions of each word or word-like utterance were tallied, but only the original utterance was counted in the analysis. For those subjects who did not produce 50 utterances on videotape, as many utterances as possible were used, with the smallest number 
of utterances being three. The mean number of utterances for the normal group was 41.38 , and the mean number of utterances transcribed for the LTs was 23.58 .

The following rules, adapted from olswang et al., were strictly followed for each sample:

1. Transcription:

a. The sample consisted of up to fifty consecutive different vocalizations, consisting of a minimum of a voiced vocalic element or a voiced syllabic consonant, produced with an egressive airstream. Any vocalization which could not be transcribed easily after four hearings (because of poor sound transmission) was eliminated. Also, any utterance which occurred simultaneously with any other sound on the tape, such as parental speech or the noise of a toy, was not transcribed.

b. In addition, the utterance could not be a cry, cough, or scream.

c. Babbled utterances were required to be bounded by one second of silence on either side or by the noises noted above, or by a breath or by adult speech. Words and word-like utterances were identified by their phoneme content (words) or by their inflection (word-like 
utterances). A full second of silence was not required.

2. Coding:

Each utterance was coded as syllable structure Level (SSL) I, II, or III. Rules for assigning SSL are as follows (adapted from olswang et al., 1987).

Level I: The utterance is composed of voiced vowel(s), voiced syllabic consonant(s), or CV syllable(s) in which the consonant is a glottal stop, a glide (i.e., $/ j /, / w /$ ), or $/ \mathrm{h} / \ldots$... Examples: /he/, /wa/, /m/, / / o/.

Level II: The utterance is composed of VC or CVC syllable(s) with a single consonantal type and $\mathrm{CV}$ syllables which do not fit the criteria for Level $I$. Disregard voicing differences... Examples: /Ap/, /kek/, /no/, /mama/i /og/, /mim/.

Level III: The utterance is composed of syllables with 2 or more consonant types. Disregard voicing differences... (Olswang et al.). Examples: / lok/, /marn/, /brenkIt/; /adas/, /bozdi/.

3. Scoring:

a. Mean SSL was then determined for each subject by adding the scores $(1,2$, or 3$)$ for each utterance and dividing by the number of utterances coded.

b. Meaningful words were identified in each sample, and percentages of meaningful words were calculated.

c. For those children who produced at least ten 
meaningful words, the meaningful words were also analyzed for percentage of consonants correctly produced, whenever the correct target form could be determined.

d. True consonant types were tallied for each subject.

The procedures described in olswang et al. were not followed in their entirety. Specifically, the sample of vocalizations transcribed for the present study was less than olswang et al. recommended, and no distinction was made, for scoring purposes, between babbled and meaningful speech. Rather, the Babbling Level scoring system was applied to both types of vocalization, and is referred to here as the Syllable structure Level. During transcription, meaningful words were identified, and all consonants were listed.

\section{RELIABILITY}

In order to determine inter-judge reliability, a reliability judge transcribed and coded ten percent of the videotapes according to the procedures described above. The reliability judge was a specially trained graduate student in Speech/Language Pathology. The videotapes used for reliability were selected by use of a random number table. This judge and the researcher transcribed the videotapes independently. A point-to-point reliability method was 
used, which indicated $85 \%$ reliability of consonant inventories and $87.72 \%$ reliability of percent consonants correct. Accuracy of coding for syllable structure levels was 87.478 . 


\section{CHAPTER IV \\ RESULTS AND DISCUSSION}

\section{RESULTS}

The data gathered from the two groups of subjects were compared in terms of mean syllable structure Level (SSL), percentage of consonants produced correctly, and number of different consonant types produced. Sub-groups based on age within both the Normal and Late Talker (LT) groups were identified in response to the questions posed in chapter $I$.

Prior to a statistical analysis of the parameters in question, tests were conducted in order to determine whether the groups were matched for age, number of utterances transcribed, and mean number of repetitions per utterance. A two-tailed student's $\underline{t}$-test indicated that the Normal and LT groups were not significantly different in terms of age. A significantly higher number of utterances was produced by the subjects in the Normal group than in the LT group, with a $\mathrm{p}^{<.005}$ level of significance. In addition, members of the Normal group repeated their own utterances significantly less frequently than did members of the LT group, at a $\mathrm{p}<.025$ level. Results of these tests are summarized in Table II. 
TABLE II

COMPARISON OF AGES, NUMBER OF UTTERANCES, AND NUMBER OF REPETITIONS PER UTTERANCE, BY GROUP

\begin{tabular}{|c|c|c|c|}
\hline & $\begin{array}{l}\text { Age in } \\
\text { Months }\end{array}$ & $\begin{array}{l}\text { Number of } \\
\text { Utterances }\end{array}$ & $\begin{array}{l}\text { Repetitions } \\
\text { per Utterance }\end{array}$ \\
\hline Mean & 25.33 & 41.38 & 2.05 \\
\hline \multirow[t]{3}{*}{ Standard Deviation } & 4.90 & 14.64 & .4356 \\
\hline & \multicolumn{2}{|c|}{ LT Group $(n=28)$} & \\
\hline & $\begin{array}{l}\text { Age in } \\
\text { Months }\end{array}$ & $\begin{array}{l}\text { Number of } \\
\text { Utterances }\end{array}$ & $\begin{array}{l}\text { Repetitions } \\
\text { per Utterance }\end{array}$ \\
\hline Mean & 24.93 & 23.5 & 3.25 \\
\hline Standard Deviation & 3.99 & 16.43 & 2.2 .61 \\
\hline $\begin{array}{l}\text { Significance } \\
\text { of Difference }\end{array}$ & N.S. & $\mathrm{p}<.005$ & $\mathrm{p}<.025$ \\
\hline
\end{tabular}

Tests of Hypotheses Regarding Group Differences

A. Hypothesis: The mean syllable structure Level (SSL) of the Normal group is not significantly higher than the mean SSL of the LT group.

A one-tailed student's $\underline{t}$ test was performed. The mean SSL for the Normal group $(n=24)$ was 2.3 , (standard deviation, 0.2). The mean SSL for the LT group ( $\mathrm{n}=28$ ) was 1.7 , (standard deviation, 0.4). The mean SSL of the Normal group was significantly higher than that of the LT group, at a $p<.05$ 
level. These results are summarized in Table III.

\section{TABLE III}

COMPARISON OF MEAN SSLS OF THE NORMAL AND LT SUBJECTS

Normal

Group $(n=24)$
LT Group $(n=28)$
Significance of Difference

$\mathrm{p}<.05$

B. Hypothesis: The mean number of different consonant types of the Normal group is not significantly higher than the mean number of different consonant types of the LT group.

A one-tailed student's $\underline{t}$ test was performed. The mean number of different consonant types for the Normal group ( $n=24$ ) was 16.5 , (standard deviation, 3.5). The mean number of different consonant types for the LT group ( $n=28$ ) was 8.7 , (standard deviation, 4.9). The mean number of different consonant types of the Normal group was significantly higher than the number of different consonant types of the LT group, at a $\mathrm{p}<.005$ level. These results are summarized in Table IV. 
TABLE IV

COMPARISON OF MEAN NUMBER OF DIFFERENT CONSONANT TYPES OF THE

NORMAL AND LT SUBJECTS

Mean number of consonant types Standard Deviation 16.46

3.476

8.71

4.936

$\mathrm{p}<.005$

c. Hypothesis: The mean percentage of consonants correctly produced by the Normal group is not significantly higher than the mean percentage of consonants correctly produced by the LT group.

A one-tailed Student's $t$ test was performed. For this test, only the scores of those subjects who produced at least ten meaningful words were used. These two groups were not significantly different in age. The percentage of consonants produced correctly by the Normal group $(\mathrm{n}=22$ ) was 66.5 , (standard deviation, 18.8). The percentage of consonants produced correctly by the LT group ( $n=13$ ) was 56.2, (standard deviation, 11.656). The percentage of consonants produced correctly by the Normal group was significantly higher than the percentage of consonants produced correctly by the LT group, at a $\mathrm{p}<.05$ level. These results are summarized in Table $\mathrm{V}$. 


\section{TABLE V}

COMPARISON OF CORRECT CONSONANTS OF THE NORMAL AND LT SUBJECTS PRODUCING MORE THAN

TEN MEANINGFUL WORDS

Normal

Group ( $n=22)$
LT Group $(n=13)$
Significance of Difference

Mean percent of consonants correct 66.527 Standard Deviation

\section{Sub-Groups}

Sub-groups were identified based on the subjects' ages, as few distinct patterns emerged from the data. The median age of the subjects in both the Normal and LT groups was 25 months. The "older groups" consisted of subjects 26 months old and older; the "younger groups", 25 months and younger. The Normal and LT older groups were well matched for age, as were the Normal and LT younger groups, with no significant differences between them on t-tests.

statistical tests were performed in order to compare the scores of the older subjects in the LT group with their counterparts in the Normal group on each variable tested above. The two groups of younger subjects were also compared. Each test indicated that the scores of the Normal subjects were significantly higher than the scores of their LT peers.

The following tests were performed in order to determine whether the older subjects in each group scored 
significantly higher on each variable than did the younger subjects within the same group.

1. Hypothesis: The mean SSL's of older subjects are not significantly higher than those of younger subjects. a. Within the Normal group. A one-tailed Student's $\underline{t}$ test was performed. The SSL for the older group $(n=11)$ was 2.4, (standard deviation, 0.11). The SSL for the younger group $(\mathrm{n}=13)$ was 2.2 , (standard deviation, $0.26)$. The mean SSL of the older subjects was not significantly higher than the mean SSL of the younger subjects.

b. Within the LT group. A one-tailed student's $\underline{t}$ test was performed. The mean SSL for the older group $(n=13)$ was 1.7 , (standard deviation, 0.35). The mean SSL for the younger group $(n=15)$ was 1.6, (standard deviation, $0.39)$.

The mean SSL of the older subjects was not significantly higher than the mean SSL of the younger subjects. These results are summarized in Table VI. 
TABLE VI

COMPARISON OF MEAN SSLS OF THE

YOUNGER AND OLDER SUBJECTS

WITHIN THEIR GROUPS

\begin{tabular}{|c|c|c|c|c|}
\hline \multicolumn{5}{|c|}{ Normal Group } \\
\hline & $\begin{array}{l}\text { Older } \\
\text { Group }\end{array}$ & $(n=11)$ & $\begin{array}{l}\text { Younger } \\
\text { Group }(n=13)\end{array}$ & $\begin{array}{l}\text { Significance of } \\
\text { Difference }\end{array}$ \\
\hline $\begin{array}{l}\text { Mean SSL } \\
\text { Standard }\end{array}$ & Deviation & $\begin{array}{l}2.4 \\
.11\end{array}$ & $\begin{array}{r}2.2 \\
.26\end{array}$ & NS \\
\hline \multicolumn{5}{|c|}{ LT Group } \\
\hline & $\begin{array}{l}\text { Older } \\
\text { Group }\end{array}$ & $(n=13)$ & $\begin{array}{l}\text { Younger } \\
\text { Group }(n=15)\end{array}$ & $\begin{array}{l}\text { Significance of } \\
\text { Difference }\end{array}$ \\
\hline $\begin{array}{l}\text { Mean SSL } \\
\text { Standard }\end{array}$ & Deviation & $\begin{array}{l}1.7 \\
.35\end{array}$ & $\begin{array}{l}1.6 \\
.39\end{array}$ & NS \\
\hline
\end{tabular}

2. Hypothesis: The number of different consonant types produced by older subjects is not significantly higher than the number of different consonant types produced by younger subjects. a. Within the Normal group. A one-tailed student's $\underline{t}$ test was performed. The number of different consonant types produced by the older group $(n=11)$ was 18.5, (standard deviation, 1.78). The number of true consonants produced by the younger group $(n=13)$ was 14.7, (standard deviation, 3.66). Within the Normal group, the number of different consonant types produced by the older subjects was significantly higher than the number of different consonant types of the younger subjects, at a $\mathrm{p}<.05$ 
level.

b. Within the LT group. A one-tailed student's $\underline{t}$ test was performed. The number of different consonant types produced by the older group $(n=13)$ was 11.0 , (standard deviation 5.29). The number of true consonants produced by the younger group $(n=15)$ was 6.7 , (standard deviation, 3.73).

The number of different consonant types produced by the older LT subjects was significantly higher than the number of different consonant types produced by the younger LT subjects, at a $\mathrm{p}<.05$ level.

These results are summarized in Table VII.

TABLE VII

COMPARISON OF DIFFERENT CONSONANT TYPES OF THE OLDER AND YOUNGER SUBJECTS

BY GROUP

Normal Group

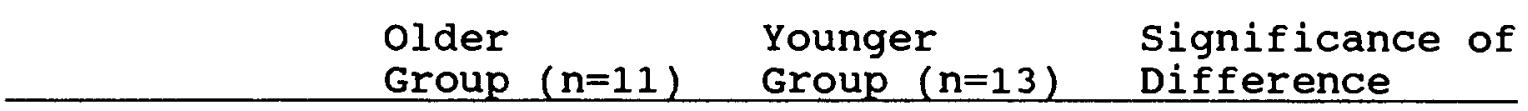

Mean number of Consonant types

Standard Deviation 1.78
18.5
14.7

$\mathrm{p}<.05$

3.66

\section{LT Group}

\begin{tabular}{lll} 
Older & $\begin{array}{l}\text { Younger } \\
\text { Group ( } n=13)\end{array}$ & $\begin{array}{l}\text { Significance of } \\
\text { Difference }\end{array}$ \\
\hline
\end{tabular}

$\begin{array}{lccc}\text { Mean number of } & 11.0 & 6.7 & \mathrm{p}<.05 \\ \text { Consonant types } & & 3.73 & \\ \text { Standard Deviation } & 5.29 & 3.7\end{array}$


3. Hypothesis: The percent correctly produced consonants of older subjects is not higher than that of younger subjects. Only subjects who produced 10 or more meaningful words were included. a. Within the Normal group. A one-tailed Student's $\underline{t}$ test was performed. The mean percent of correctly produced consonants for the older group $(n=11)$ was 77.1, (standard deviation, 11.6). The mean percent of correctly produced consonants for the younger group $(n=11)$ was 55.99 , with a standard deviation of 19.6 . Within the Normal group, the percent of correctly produced consonants of the older subjects was significantly higher than the percent of correctly produced consonants of the younger subjects, at a $\mathrm{p}<.005$ level.

b. Within the LT group. A one-tailed student's $\underline{t}$ test was performed. The mean percent of correctly produced consonants for the older group $(n=8)$ was 59.1, (standard deviation, 12.7). The mean percent of correctly produced consonants for the younger group $(n=5)$ was 51.58, (standard deviation, 9.06). Within the LT group, the percent of correctly produced consonants of the older subjects was not significantly higher than the percent of correctly produced consonants of the younger subjects. These results are summarized in Table VIII. 
TABLE VIII

COMPARISON OF CORRECT CONSONANTS OF THE

OLDER AND YOUNGER SUBJECTS

BY GROUP

\section{Normal Group}

\begin{tabular}{lll} 
Older & $\begin{array}{l}\text { Younger } \\
\text { Group }(n=11)\end{array}$ & $\begin{array}{l}\text { Significance of } \\
\text { Difference }\end{array}$ \\
\hline
\end{tabular}

Mean percent of

77.1

55.99

$p<.05$

correct consonants

Standard Deviation

11.6

19.6

\section{LT Group}

\begin{tabular}{lll} 
Older & $\begin{array}{l}\text { Younger } \\
\text { Group }(n=8)\end{array}$ & $\begin{array}{l}\text { Significance of } \\
\text { Difference }\end{array}$ \\
\hline
\end{tabular}

Mean percent of

59.1

51.58

NS

correct consonants

Standard Deviation

12.7

9.06

\section{Observations}

In addition to those results which were obtained by statistical testing of the data, the researcher wishes to note the following observations.

The first observation concerns the group of Normal subjects. From the data, the age of twenty-five months appears to be a pivotal point in speech development. The subjects under twenty-six months produced between 10 and 50 different utterances during the ten-minute recording sessions, and the percentage of the utterances which were considered meaningful ranged from $25 \%$ to $100 \%$. Variability in these factors was noted within each month of age, up to 26 months. Great variability was also noted in the other 
variables, up to 26 months. However, beginning with the twenty-six month olds, the Normal group is much more homogeneous on all variables. For example, only one subject in the older group, a 26 month old, produced less than 50 utterances in ten minutes, and that subject produced 49 utterances.

F Tests for the Comparison of Population Variances were conducted, in order to determine whether there was significantly higher variation in the scores of the younger subgroups than the older subgroups, in each of the three variables. The results of these tests are summarized in Table IX.

The younger Normal groups had significantly higher variability of mean SSL and number of different consonants than did the older Normal group. The younger group also had higher variance on percent consonants correct, although this was not statistically significant at the $\mathrm{p}=.05$ level.

Because of the relatively low variability of the scores of the older Normal group, the ranges of these scores might be used as a profile of scores to describe older Normal toddler phonology. This profile is given in Table $x$. It should be noted that, while the range of scores for each variable in the LT group overlaps the range of the normal group's scores, no member of the LT group obtained more than three scores within the range of the normal group, while every member of the older normal group had all five scores within that range. 
TABLE IX

\section{COMPARISON OF VARIANCES \\ BETWEEN SUB-GROUPS}

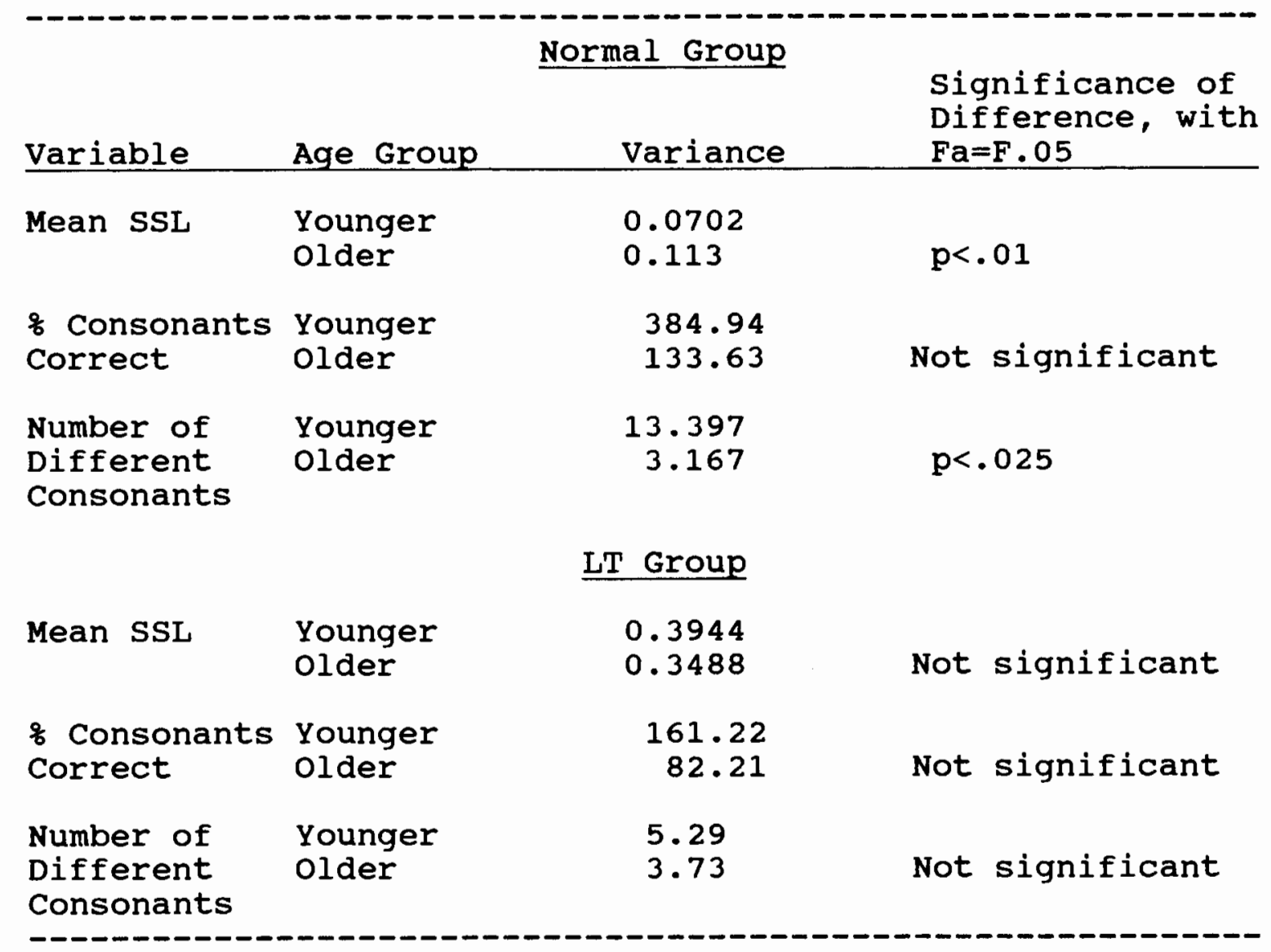




\section{TABLE X}

RANGES OF SCORES ON FIVE VARIABLES FOR THE OLDER NORMAL AND LT SUB-GROUPS

IN A TEN-MINUTE SPEECH SAMPLE, UP TO FIFTY UTTERANCES.

\section{Variable:}

Number of Utterances

Percent Meaningful Utterances

SSL

\% Correct Consonants (Based on at least 10 meaningful words)
Range:

\begin{tabular}{ll} 
Normal & LT \\
\hline $49-50$ & $3-50$
\end{tabular}

$90-100$

$0-88$

$2.24-2.56$

$1.00-2.40$

$61-99$

41-83 


\section{DISCUSSION}

The results of this study indicate that children in this age group with normally developing expressive language have more advanced phonological development in terms of syllable structures, percent consonants correct in meaningful speech, and number of different consonant types produced, than do children whose language development is slow. Furthermore, the results indicate that the accuracy of consonant production of children with normal language development tends to improve over time, while the accuracy of LTs tends to remain relatively stable over the age range studied. Children whose language development is normal show less individual variation in phonological development than their late talking peers, and the individual variation decreases for the Normal group as the age of the group increases, particularly after 25 months.

No patterns were found in the data which consistently identified any group, although the older group of normal subjects had somewhat more homogeneous scores.

In addition to answering the questions posed in Chapter one, the results can be compared to the results of other selected research, for example, Ingram's (1976) study of the first fifty words of four normally developing children gave an indication of what syllable types to expect in the 
meaningful speech of young children. The syllable types included primarily $\mathrm{CV}, \mathrm{CVCV}$ reduplicated, and some occurrences of VC and CVC syllables. Production of these syllable types in this distribution would cause a subject's speech to be rated in the 1.00-2.00 Syllable Structure Level range, if coded according to the guidelines for the present study. In the present study, the data show that the mean Syllable Structure Level of the LT group is 1.68, which indicates that the utterances produced by these subjects consist of syllable types similar to the normal children's first words in the Ingram study. In contrast, the mean SSL of the Normal group, 2.3, indicates a much higher use of CVC syllables, thus demonstrating growth in the production of syllable structures.

It is not possible to compare the results of the present study directly with the results of olswang et al. (1987), because of the difference in the ages of the subjects in the two studies. However, it is possible to report the findings of this study regarding the parameters measured by olswang et al. The first parameter to be compared is phonological complexity of babbled, or in the case of the present study, babbled and meaningful, utterances. Both studies used the syllable structure as a measure of phonological complexity. olswang et al. found that babbled utterances increased in complexity between the ages of nine and 18 months. The present study, in which all 
except one of the subjects were 18 months or older, indicated that the SSLs of normal speakers 26 months through 37 months old are significantly higher than the SSLs of normal speakers 16 through 25 months old. Because of the relatively small sample size, further analysis by age was not possible. However, these results indicate that phonological complexity continues to increase, in normal speakers, after the age of 18 months, at least into the period of 26 through 37 months.

olswang et al. also note that, at 12 months, none of their 34 subjects was in the meaningful speech stage, but at 24 months, all subjects were using primarily meaningful speech. The present study did not directly address the proportion of meaningful speech, however, it can be noted from the data that all except two of the normal subjects, 20 and 16 months old, used more than $50 \%$ meaningful speech.

In addition, the percent of consonants correct in meaningful speech increased between the ages of 15 and 24 months, in the study by olswang et al. The results of the present study indicate that the percent of consonants correct continues to increase, in normal speakers, into the period of 26 through 37 months, while it does not increase for LT speakers.

Comparison of the variances of the Normal group's scores indicates that, while development of syllables is not completely uniform, individual differences may not be as 
prevalent as those found in studies of phoneme acquisition, especially between the ages of 26 and 37 months. The variances of the older LT group appear to be larger on all variables than those of the older Normal group. 
CHAPTER V

SUMMARY AND IMPLICATIONS

SUMMARY

Research regarding the phonological productions of very young children has typically centered on the speech of normal children, usually emphasizing the acquisition of segments, or phonemes. Although much individual variation has been observed within the normal population, norms describing broad age ranges have been established for the acquisition of segments. Because of the variability of phoneme acquisition, these norms are of limited clinical use with very young children. Several researchers have noted an increase in the complexity of syllable structures with the development of speech, although no norming data is available for syllable structure development.

In the present study, the speech of twenty-four normally speaking toddlers and twenty-eight late talking toddlers was analyzed with respect to the syllable structures produced during a speech sample. The groups were matched with regard to age, sex, and socio-economic status, all passed a hearing screening, and all scored at least 85 on the Bayley Scales of Infant Development. 
Each child was videotaped interacting with his or her mother during a ten-minute play session. The subjects' utterances were broadly transcribed from these videotapes, using IPA symbols. Fifty consecutive different words or word-like utterances, or as many as could be transcribed out of the ten minute session, were coded from each subject. Each utterance was assigned to syllable structure Level (SSL) I, II, or III, according to criteria designated by Olswang et al. (1987), and a mean SSL was calculated. Inventories of consonant types were taken for each subject. In addition, each utterance was determined to be either meaningful or babbled. Meaningful utterances were glossed, and the percentage of consonants correctly produced was determined, for those subjects who produced at least ten meaningful words.

The data were analyzed for significant differences between the two groups in the mean SSL, number of consonant types, and percent consonants correct. similarly, significant differences were sought between the older and younger sub groups within each group. The results indicated that children in this age group with normally developing expressive language have more advanced phonological development in terms of complexity of syllable structures, percent consonants correct in meaningful speech, and number of different consonant types produced, than do children who are late talking. The accuracy of phoneme production of 
children with normal language development improves over time, while that of LTs tends to remain relatively stable over the age range studied. Children with normal expressive language show less individual variation in phonological development than their late talking peers, and the individual variation decreases for the normal group as they get older, particularly after 25 months.

These data indicate that at least some children with expressive language disorders do have phonological delays. Therefore, the "general encoding deficit" described by Paul and Shriberg (1982) is supported here.

\section{IMPLICATIONS}

\section{Research Implications}

While the reliability of the present study is good, it is thought that the inferior quality of sound transmission on the videotapes may have negatively affected the accuracy of the transcriptions. The use of lapel microphones might have significantly increased the reliability of the study. The study of toddler phonology is rife with methodological difficulties. Both in the literature and in this researcher's observation, problems are encountered with recording, transcribing, and analysing the data.

The kinetic nature of children at play makes electronic recording of their utterances difficult.

A stationary microphone may miss many important utterances, while a lapel 
microphone may be used as a toy, or may be pulled off with sudden movements. In the present study, in which the subjects played on the floor of a clinic room with their mothers, a remote microphone was placed on carpet near the subject during videotaping. Because the children tended to wander away from the area, and because some of the toys used were very noisy, many utterances which were not easy to discern on the videotapes were not transcribed. Another problem encountered with the recording was the relatively poor sound quality of the videotapes. The cause of this problem is not known to this writer, however, detailed analysis of certain data, such as phonological processes, was not carried out because of the poor sound quality. Problems encountered in transcription are many. Children who are just beginning to use meaningful speech use many different phonological forms. Some utterances are obviously vocal play, or babbling. Others seem to be meaningful, because the vocal inflection used is similar to that of the adult language, although no referent is clear from the context. In utterances which are obviously meaningful, the child may use two or three surface forms within a few minutes to produce the same word. For example, the word "duck" might be produced as $/ d^{\wedge} k /, / ?^{\wedge} k /$, and $/ g^{\wedge} \mathbf{k} /$, by the same child, in a ten minute span. Conversely, a child might also produce two words which are phonemically different in English with the same phonological pattern. 
For example, "star" and "car" might both be produced as /da:/. To further complicate matters, the child might sometimes produce sounds which are not phonemic in the English language, or which are distortions of adult sounds. Idiosyncratic forms pose a similar problem. For example, Si, Macken's (1979) Spanish speaking subject, produced an unnecessary neutral syllable before 19-20 percent of her words. Other children sometimes choose a favorite sound, and spend a period of their language learning time using this one sound as often as possible, without regard for any phonological rules. It is hoped that the influence of all of these processes which occur in individual children were ameliorated by the transcription and analysis rules which were used in the present study. In particular, the measurement of Mean Syllable Structure appeared to be relatively immune to the influence of variations in the phoneme content of words.

Additional research comparing the syllable structures produced by late talking and normal children is needed, in order to develop a more clear understanding of phonological development in both groups. Replication of this study could provide information on the universality of the conclusions drawn about the phonological productions of these toddlers. Such replications in varying populations would provide additional information which might be a basis for the development of a protocol for the early differential 
diagnosis of phonological disorders.

The Syllable structure Level scale could be expanded for use with older toddlers by adding a fourth level, Level IV, in which words containing later developing consonants and multisyllabic words could be coded. This would be especially helpful in studying the productions of three- and four- year olds, and might provide a more sensitive instrument for the measurement of syllable structure development. Additional studies could investigate the use of such an expansion by using it to compare the productions of normal and late talking children at the ages of three and four.

Follow-up studies should be conducted with the subjects of this study, in order to evaluate the predictive value of the results reported here. Of particular interest would be studies at four years and six years of age and during the fourth or fifth grade in school. The focus of such investigations would be on the presence of phonological disorders and, for the older children, the presence of reading or other learning difficulties. Until this study has been replicated, and follow-up studies have been conducted, clinical application of the results must be used with caution.

\section{Clinical Implications}

While it is hoped that the SSL scale will be further refined by future researchers, the present study might 
temporarily be of clinical use to individuals who are concerned with assessment of speech production in children between 26 and 36 months. Following the procedures described in Chapter III, a child's productions during a tenminute play period with a parent could be transcribed, coded, and compared to the profile of the productions of normally developing children given in Table $x$. If the child's scores fall within the guidelines on every measure, the child's productions are similar to those of the normal children in the present study. If no score falls within the guidelines, the child is probably a late talker. Any further interpretation would not be supported by the present data, although follow-up studies may provide information which will lend predictive value to these guidelines. An additional clinical use of the results would be in observation of toddlers. The rate of verbal output, the percent of meaningful speech, the number of different syllable structure types and the number of different consonant types may all be indicators of phonological development, and very low incidence of any of these measures should be viewed with concern by the clinician.

Syllable structure Level appears to be a potentially valuable measure of phonological development in toddlers, and it is hoped that its clinical usefulness will be expanded in the near future.

Regarding treatment of language disorders in toddlers, 
the results of the study indicate that the vocabulary chosen to be taught to a child should be within the child's phonological ability. Specifically, the child's syllable structure productions should be noted, and vocabulary words with those structures should be the first taught. If the child already has a fairly sizeable expressive vocabulary, which he produces with a very limited number of syllable types, using a limited number of phonemes, additional syllable structures at the same level as his best productions should be taught, before attempts are made to expand his phonemic repertoire. For example, if the child pronounces "pop", "fall", "ball", "paper" and "put", all as /pa/, the first word to be taught would be "pop", because it has a Level II syllable structure. Other CVC and VC words which contain this child's available phonemes would also be taught at this time. Once the child is producing Level II words with accuracy, Level III syllable structures can be introduced, still using the child's own phonetic inventory. 
Bayley, N. (1969). Bayley Scales of Infant Development. New York, NY: The Psychological Corporation.

Dale, D.S., Bates, E., Reznick, S.J., and Morisset, C. (1989). The validity of a parent report instrument of child language at twenty months. Journal of Child Language, 16, 239-250.

Dyson, A.T. (1988). Phonetic inventories of 2- and 3-year old children. Journal of Speech and Hearing Disorders, 53, 89-93

Dyson, A., and Paden, E. (1983). Some phonological acquisition strategies used by 2-year olds. Journal of Childhood Communication Disorders, 7, 6-18.

Edwards, M.L. and Shriberg, L.D. (1983) - Phonology: Applications in communication disorders. San Diego, CA: College-Hill Press.

Ferguson, C., and Farwell, C., (1975). Words and sounds in early language acquisition: English initial consonants in the first fifty words. Language, 15, 1-54.

French, A. (1989). The systematic acquisition of word forms by a child during the first-fifty-word stage. Journal of Child Language, 16, 69-90.

Gill, C.B. (1987). A longitudinal study of phonemic and phonological process development of a language disordered subject. unpublished doctoral dissertation, cited in Dissertation Abstracts International, $47,10,3730-A$.

Haelsig, P.C. and Madison, C.L. (1986). A study of phonological processes exhibited by 3-, 4-, and 5year old children. Language, Speech, and Hearing Services in the Schools, 17, 107-114.

Hare, G. (1983). Development at 2 years. In J. Irwin and S. Wong (Ed.s), Phonological Development in Children 18 to 72 Months. Carbondale, Il: Southern Illinois University Press. 
Hodson, B. and Paden, E. (1981). Phonological Processes which characterize unintelligible and intelligible speech in early childhood. Journal of Speech and Hearing Disorders, $46,369-373$.

Ingram D. (1976). Phonological disability in children. New York: Elsvier.

Irwin, 0. (1947a). Infant speech: Consonantal sounds according to place of articulation. Journal of Speech and Hearing Disorders, 12, 397-401.

Irwin, o. (1947b). Infant speech: Consonantal sounds according to manner of articulation. Journal of Speech and Hearing Disorders, 12, 402-404.

Irwin, 0. (1948). Infant speech: Developmental vowel sounds. Journal of Speech and Hearing Disorders, 13, 31-34.

Larkins, P. (1983). Development at 3 years. In J. Irwin and S. Wong (Ed.s), Phonological Development in Children 18 to 72 Months. Carbondale, Il: Southern Illinois University Press.

Leonard, L.B., Newhoff, M., and Mesalam, L. (1980). Individual differences in early child phonology. Applied Psycholinguistics, 1, 7-30.

Macken, M.A. (1979). Developmental reorganization of phonology: A heirarchy of basic units of acquisition. Lingua, $49,11-49$.

Matthei, E.H. (1989). Crossing boundaries: More evidence for phonological constraints on eauly multi-word utterances. Journal of Child Language, 16, 41-53.

Menn, L. (1980). Phonological theory and child phonology. In C. Ferguson, J. Kavanaugh, and G. Yeni-Komshian (Ed.s), Child Phonology, Volume 1: Production. New York: Academic Press.

Menn, L. (1985). Phonological development: Learning sounds and patterns. In J. Berko-Gleason (Ed.), The Development of Language. Columbus, $\mathrm{OH}$ : Charles $\mathrm{E}$ Merrill Publishing Company.

Menyuk, P., Menn, L., and Silber, R. (1986). Early strategies for the preception and production of words and sounds. In P. Fletcher and M. Garman (Ed.s), Language acquisition: Studies in first language development. New York: Cambridge University Press. 
Meyers, J.K., and Bean, L.L., (1965). A decade later: A follow-up of social class and mental illness. New York, NY: Wyley and Sons.

olswang, L.B., Stoel-Gammon, C., Coggins, T.E., and Carpenter, R.L. (1987). Assessing prelinguistic and early linguistic behaviors in developmentally young children. Seattle, WA: University of Washington Press.

Paschall (1983). Development at 18 months. In J. Irwin and S. Wong (Ed.s), Phonological Development in Children 18 to 72 Months. Carbondale, Il: Southern Illinois University Press.

Prather, E., Hedrick, D., and Kern, C. (1975). Articulation development in children aged two to four years. Journal of Speech and Hearing Disorders, 40, 179-191.

Preisser, D.A., Hodson, B.W., and Paden, E.P. (1988). Developmental phonology: 18-29 months. Journal of Speech and Hearing Disorders, 53, 125-130.

Paul, R. (1989). Profiles of toddlers with delayed expressive language development. Paper presented at ASHA, St. Louis, MO.

Paul, R. and Shiffer, M. (1987). An examination of communication intentions in speech delayed toddlers. Paper presented at the ASHA National Convention, New orleans, LA.

Paul, R. and Shriberg, L. (1982). Associations between phonology and syntax in speech delayed children. Journal of Speech and Hearing Research, 25, 536-547.

Rescorla, L. (1989). The language development survey: A screening tool for delayed language in toddlers. Journal of Speech and Hearing Disorders, 54, 587-599.

Reznick, S.J. and Goldsmith, L. (1989). A multiple form word production checklist for assessing early language. Journal of Child Language, 16, 91-100.

Sander, E. (1972). When are sounds learned? Journal of Speech and Hearing Disorders, 37, 55-63.

Schwartz, R., Leonard, L., Folger, M., and Wilcox, M. (1980) Early phonological behavior in normal-speaking and language-disordered children. Evidence for a synergistic view of linguistic disorders. Journal of Speech and Hearing Disorders, 45, 357-377. 
Shibamoto, J.S., and olmsted, D.L. (1978). Lexical and syllabic patterns in phonological acquisition. Journal of Child Language, $\underline{5}, 417-456$.

Smith, N.V. (1973). The acquisition of phonology: A case study. New York: Cambridge University Press.

Stoel-Gammon, C. (1987). Phonological skills of 2-year-olds. Language, Speech, and Hearing Services in the schools, $18,323-329$.

Stoel-Gammon, C. (1989). Prespeech and early speech development of two late talkers. First Language, 9, 207-224.

Stoel-Gammon, C. and Dunn C. (1985). Normal and disordered phonology in children. Baltimore: University Park Press.

Vihman, M.M., Ferguson, C., and Elbert, M. (1986). Phonological development from babbling to speech: Common tendencies and differences. Applied Psycholinguistics, Vol. 7 .

Vihman, M.M. and Greenlee, M. (1987). Individual differences in phonological development: Ages one and three years. Journal of Speech and Hearing Research, 30, 503-521. 
APPENDIX A

PARENT LETTER AND QUESTIONNAIRE 
COLLCLO:

DSIKALL AKTS AND SCIENCES

DEPARTMENT OF

SHECH COMAUUNICATION

SPEECH AND

HEARINC SCIENCES

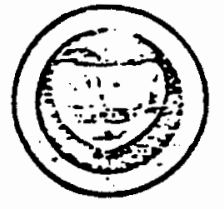

PORTLAND

STATE

UNIVERSIT:

P.O $80 \times-31$

PORTLAND CBRICON

9:20:

$503 / 229.3533$

\section{June 4, 1986}

\section{Dear frarents,}

Whe are trying to learn more about at what age children begin speaking, and what kinds of words they use when they start to ta ik. We would appreciate it greatly if you would answer the following questions and return this form to the nurse before you leave the office. Your cooperation in this study is voluntary and if you choose not to complete the ouestionnaire it will in no way affect the treatment you receive at Kaiser Permanente, at Portland State University or anywhere else. If you choose to fill out the questionnaire, I wou id appreciate your including your phone number so that I may contact you in case I have a question.

We would like to study a few children in greater depth, as well. If you would be interested in this later part of the study, please indicate so at the bottom of the cuestionnaire and give your name, aodress, and phone number. Aga in, your cooperation is completely voluntary. If you have any ouestions about the study, or about your child's speech, please do not hes itate to call me at Portland State University at 229-3142.

Thank you in advance for your help.

Yours,

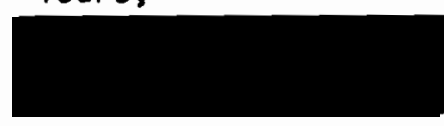

Rhea Paul, Ph.D.

Assistant Professor

$R P: m v$

Encl. 
FOR PARENTS OF CHILDREN 15-30 MONTHS OLD

What is your child's:

First name?

Date of birth?

Mother's occupation?

Father's occupation?

Mother's phone number?

How many different words can your child say? (It's OK if the words aren't entirely clear, as long as you understand them.)

none

less than 5 $10-30$

5-10 $30-50$ more than 50

If you child says fewer than ten words, please list them here:

Does your child put words together to form short "sentences"?

Yes No If yes, please give three examples here:

Would you be interested in participating in later parts of this study? Yes No

Thank you for your help! 
APPENDIX B

DEMOGRAPHIC DATA 
DEMOGRAPHIC INFORMATION FOR THE GROUP

OF NORMALLY DEVELOPING SUBJECTS

\begin{tabular}{|c|c|c|c|c|}
\hline Su & in Months & Sex & Race & SES \\
\hline 14 & 25 & $\mathbf{m}$ & White & 1 \\
\hline 27 & 22 & $\mathbf{m}$ & White & 4 \\
\hline 32 & 28 & $\mathbf{m}$ & Black & 4 \\
\hline 36 & 26 & $f$ & White & 1 \\
\hline 39 & 22 & $\mathbf{m}$ & white & 2 \\
\hline 41 & 21 & $\mathbf{m}$ & White & 2 \\
\hline 50 & 24 & m & White & 1 \\
\hline 55 & 26 & $\mathbf{f}$ & White & 3 \\
\hline 56 & 21 & $f$ & White & 1 \\
\hline 58 & 32 & $f$ & White & 1 \\
\hline 59 & 37 & $f$ & White & 3 \\
\hline 63 & 19 & $\mathrm{~m}$ & White & 3 \\
\hline 69 & 16 & $\mathrm{~m}$ & Mixed & 3 \\
\hline 72 & 20 & $\mathrm{~m}$ & White & 4 \\
\hline 81 & 25 & $f$ & White & 5 \\
\hline 113 & 25 & $\mathbf{f}$ & White & 3 \\
\hline 126 & 29 & $f$ & White & 1 \\
\hline 128 & 27 & $\mathrm{~m}$ & White & 2 \\
\hline 129 & 33 & $\mathrm{~m}$ & white & 5 \\
\hline 130 & 29 & $\mathrm{~m}$ & White & 3 \\
\hline 131 & 31 & $\mathrm{~m}$ & White & 2 \\
\hline 132 & 20 & $\mathrm{~m}$ & Mixed & 1 \\
\hline 133 & 27 & $\mathrm{~m}$ & White & 4 \\
\hline 138 & 24 & m & White & 3 \\
\hline
\end{tabular}


DEMOGRAPHIC INFORMATION FOR THE GROUP OF EXPRESSIVELY DELAYED SUBJECTS

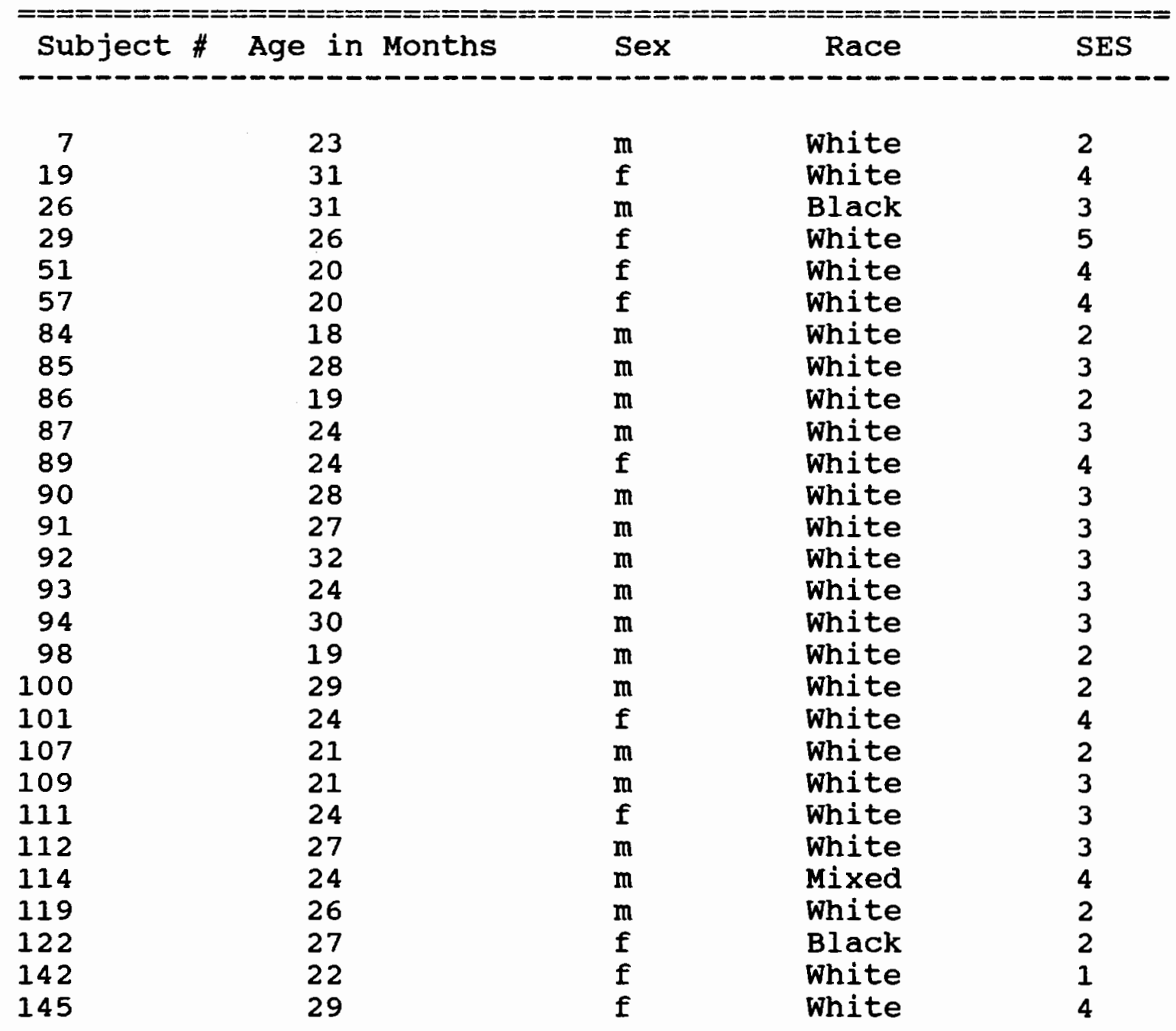


APPENDIX $C$

LETTER TO PARENTS AND CONSENT FORM 
COLLEGE OF

LIBERAL ARTS AND SCIENCES

DEPARTMENT OF

SPEECH COMMUNICATION

SPEECH AND

HEARING SCIENCES

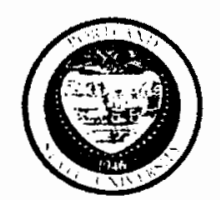

PORTLAND

STATE

UNIVERSITY

P.O. BOX 751

PORTLAND. CREGGON

97207

$503 / 229.3533$

\section{Dear Parents,}

We would like to invite you and your child to participate in a study of language development in toddlers. We hope to learn more about the age range that is normal for the beginning of speech and how children communicate in other ways during the toddler period. If you agree to join the study, you will be asked to bring your child to PSU for testing sessions every 6-12 months. At each session the child will be videotaped playing with you and some toys. We will ask the child to identify some pictures and act out some instructions with toys (such as "Push the car.") In addition we will ask you to answer some questions about the child's social and self-help skills. All parents participating will receive counseling and a list of suggestions for fostering language growth in children under three years of age. The potential benefits of the study are some help for you with stimulating language in your child. In addition, any child who reaches age three and appears to be having problems with language-learning can be referred for services in our clinic or elsewhere.

If you decide not to participate, of course the services you receive from your child's pediatrician, PSU, or any other agency will not be affected. If you decide to join the study you may withdraw at any time.

All results of your child's evaluations will remain strictly confidential. However, if you would like them to be communicated to your pediatrictan or anyone else, we will be glad to do so. There will be no charge for any work done with you or your child as part of this study.

If you have any questions, please do not hesitate to ask them, or to call me at 229-3533. Thank you for your help.

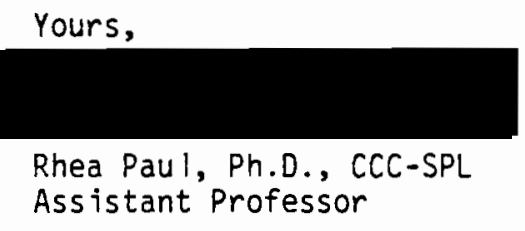

I (do) (do not) give permission for my chlld, to participate in the study described above.

I (do) (do not) give permission to show my child's videotapes for teaching or professional presentations only. I realize full names will not be used in any such presentations. 
APPENDIX D

CODING FORM 
Subj. \# Name Age

$\%$ meaningful SSL

Utterances : Exact repetitions/utterance Cons. Correct $\%$ Beginning time on tape: Ending time on tape:

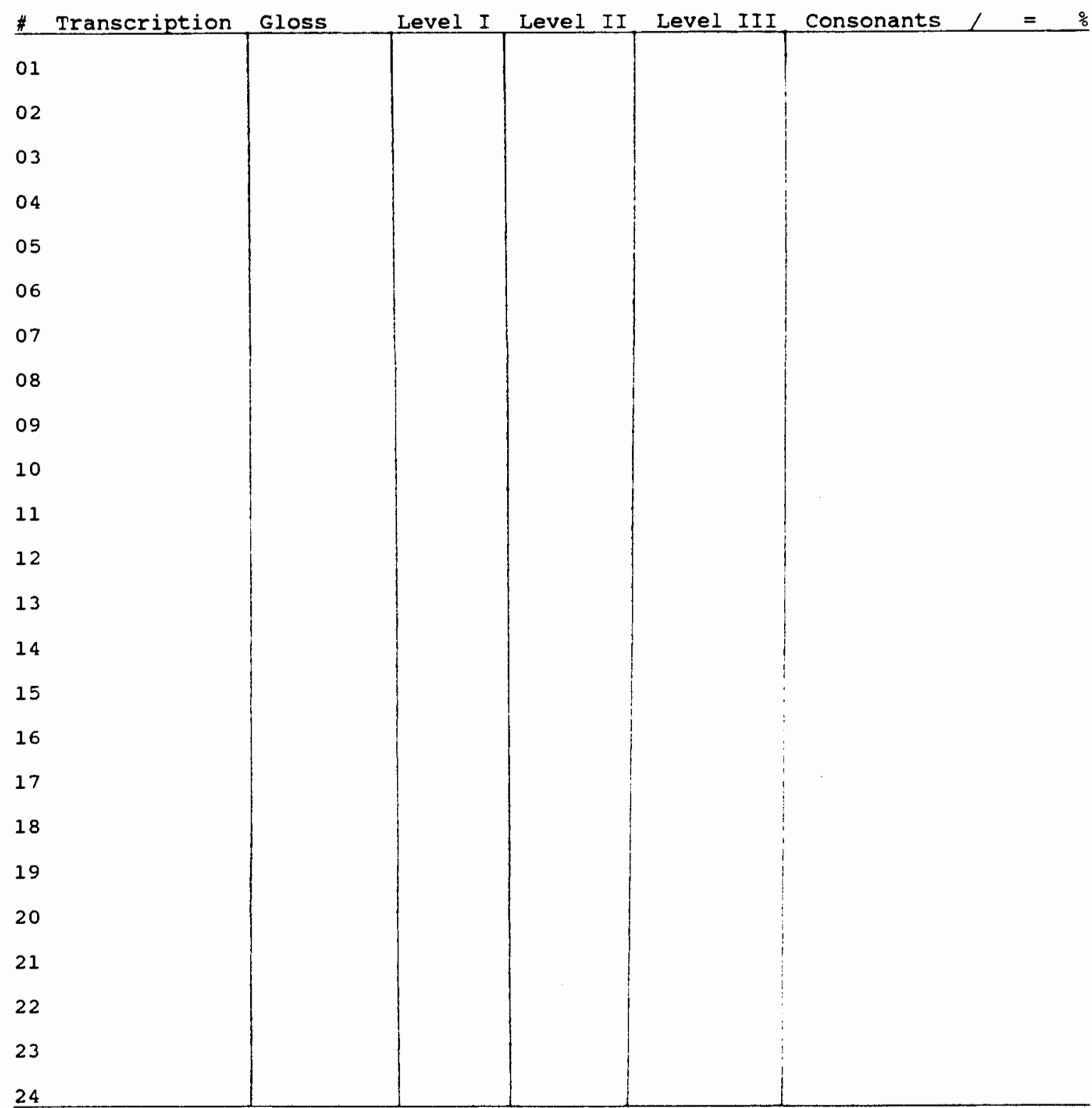




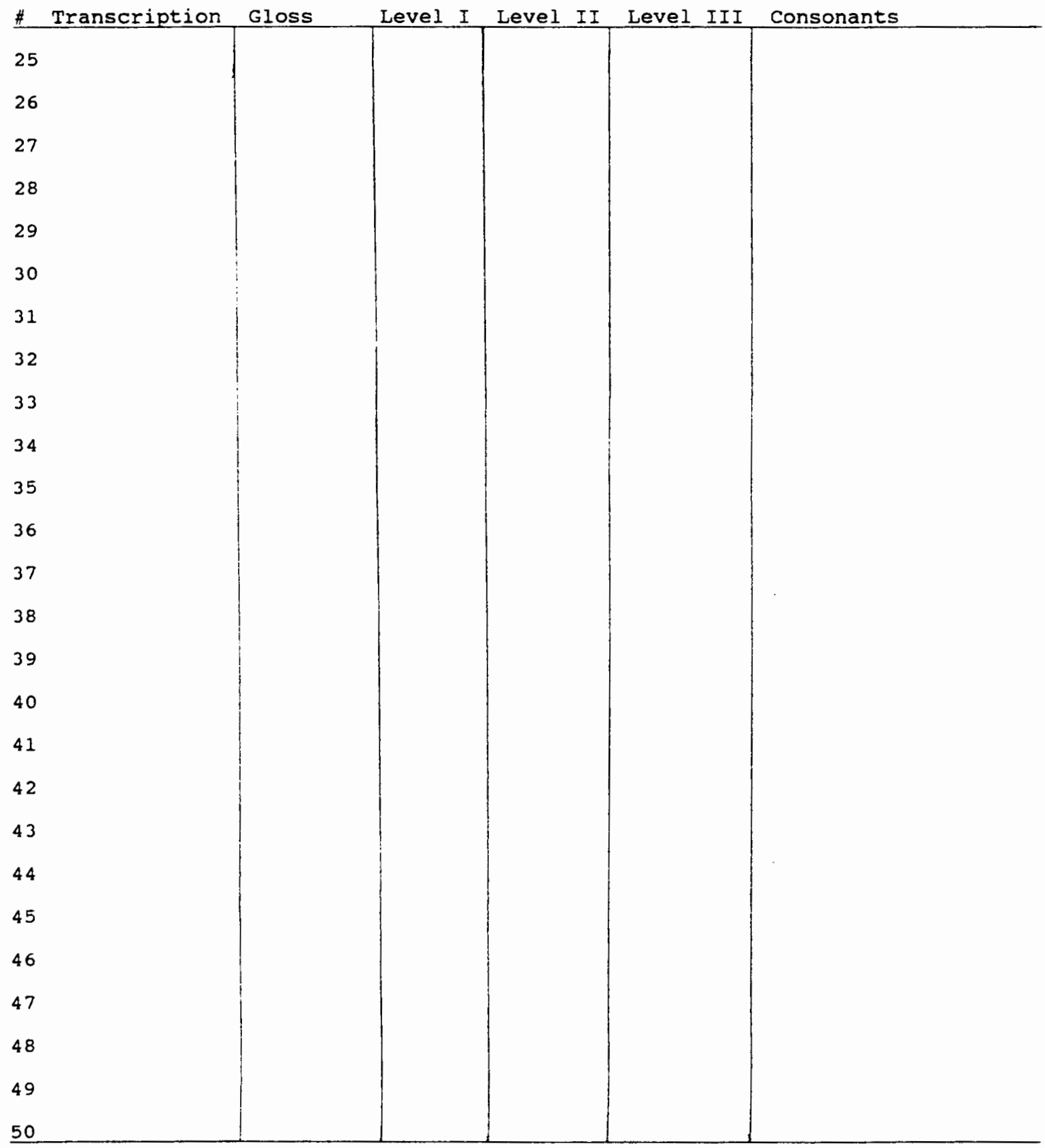

Totals: 
APPENDIX E

\section{CODING INSTRUCTIONS}


TRANSCRIPTION AND CODING INSTRUCTIONS

1. Transcription:

a. The sample consists of up to fifty consecutive different vocalizations, consisting of a minimum of a voiced vocalic element or a voiced syllabic consonant, produced with an egressive airstream. Any vocalization which can not be transcribed easily after four hearings (because of poor sound transmission) is to be eliminated. Also, any utterance which occurrs simultaneously with any other sound on the tape, such as parental speech or the noise of a toy, is not transcribed.

b. In addition, the utterance will not be a cry, cough, or scream.

c. Babbled utterances are required to be bounded by the noises noted above or by a breath, or by adult speech. Words and word-like utterances are identified by their phoneme content (words) or by their inflection (word-like utterances). A full second of silence is not required.

2. Coding:

Each utterance is coded as Syllable structure Level (SSL) I, II, or III. Rules for assigning SSL are as follows (adapted from olswang et al., 1987).

Level I: The utterance is composed of voiced vowel(s), 
voiced syllabic consonant(s), or CV syllable(s) in which the consonant is a glottal stop, a glide (i.e., $/ j /, / w / l$, or $/ \mathrm{h} /$... Examples: /he/, /wa/, /m/, / o / . Level II: The utterance is composed of VC or CVC syllable(s) with a single consonantal type and CV syllables which do not fit the criteria for Level I. Disregard voicing differences...Examples: $/ \wedge \mathrm{p} /, / \mathrm{kek} /$, /no/, /mama/; /og/, /mim/.

Level III: The utterance is composed of syllables with 2 or more consonant types. Disregard voicing differences...(Olswang et al.). Examples: $/ 10 \mathrm{k} /$, /maIn/, /bxnkIt/; /adas/, /bozdi/.

\section{Scoring:}

a. Mean SSL is then determined for each subject by adding the scores $(1,2$, or 3 ) for each utterance and dividing by the number of utterances coded.

b. Meaningful words are to be identified in each sample, and percentages of meaningful words are to be calculated.

c. For those children who produced at least ten meaningful words, the meaningful words are to be analyzed for percentage of consonants correctly produced, whenever the correct target form can be determined.

d. True consonant types are to be tallied for each subject. 
APPENDIX F

SUBJECT DATA 
DATA FROM THE NORMAL GROUP older subjects

Subj. Age \#Utter- Repeti- $\frac{\circ}{6}$ Mean- SSL $\%$ correct \# true No. ances tions ingful consonants cons.

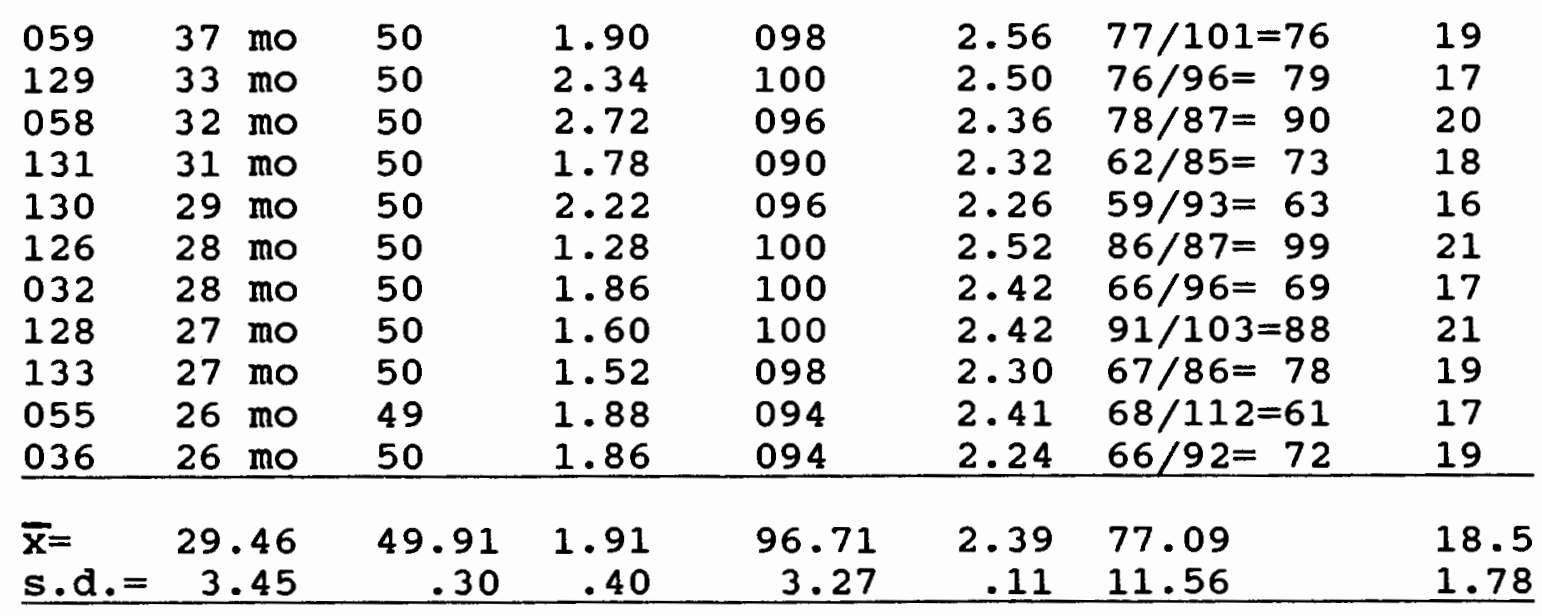

Younger Subjects

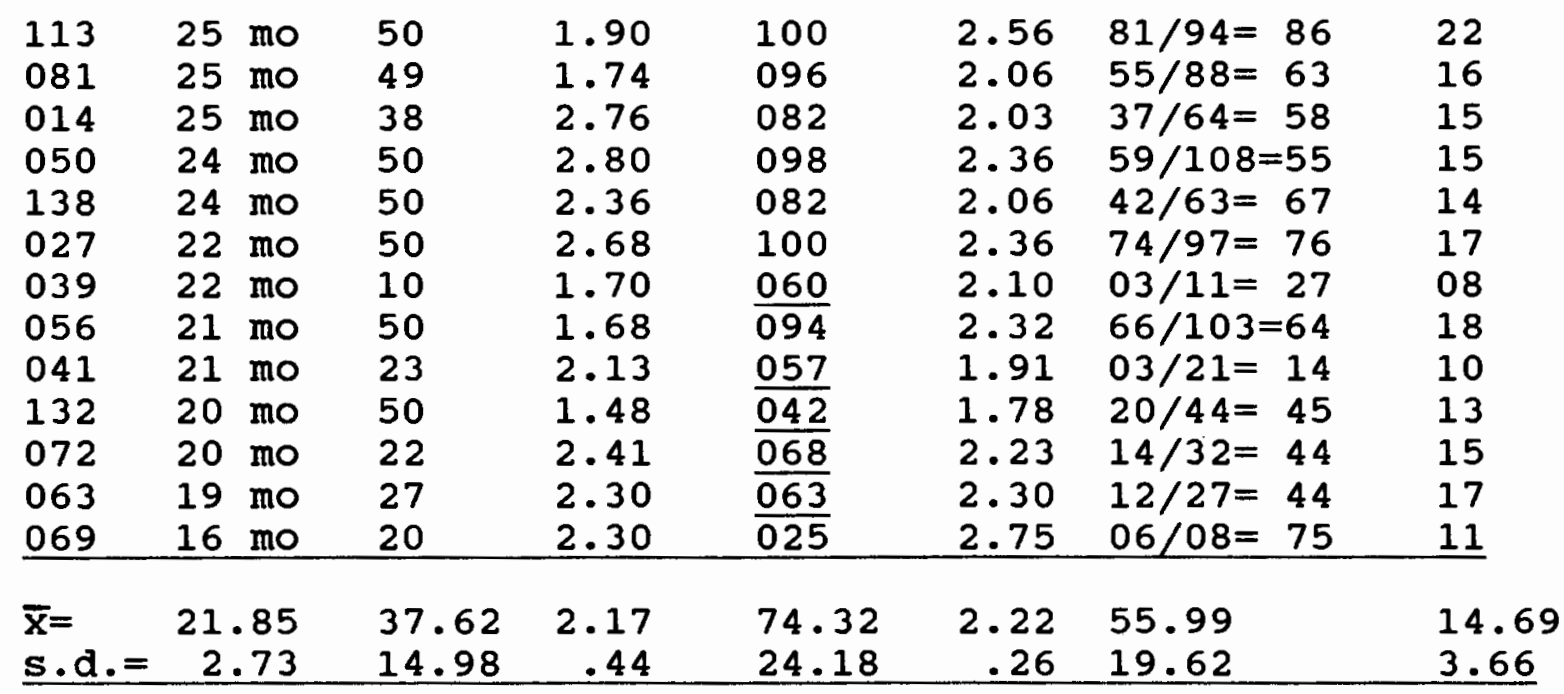

\section{MEANS AND STANDARD DEVIATIONS} FOR THE NORMAL GROUP

Subj. Age \#Utter- Repeti- $\%$ Mean- SSL \& correct \# true No. ances tions ingful consonants cons.

\begin{tabular}{lrrrrrrr}
$\bar{X}=$ & 25.33 & 41.38 & 2.05 & 84.67 & 2.30 & 66.53 & 16.46 \\
s.d. $=$ & 4.90 & 14.64 & .44 & 21.02 & .22 & 18.84 & 3.48 \\
\hline
\end{tabular}


DATA FROM THE LATE TALKER GROUP older subjects

Subj. Age \# Utter-Repeti- $\%$ Mean- SSL 8 correct \# true No. ances tions ingful consonants cons.

\begin{tabular}{|c|c|c|c|c|c|c|c|c|}
\hline $\begin{array}{l}092 \\
026 \\
019 \\
094 \\
100 \\
145 \\
090 \\
085 \\
122 \\
091 \\
112 \\
029 \\
119 \\
\end{array}$ & $\begin{array}{l}32 \\
31 \\
31 \\
30 \\
29 \\
29 \\
28 \\
28 \\
27 \\
27 \\
27 \\
26 \\
26 \\
\end{array}$ & $\begin{array}{l}\text { mo } \\
\text { mo } \\
\text { mo } \\
\text { mo } \\
\text { mo } \\
\text { mo } \\
\text { mo } \\
\text { mo } \\
\text { mo } \\
\text { mo } \\
\text { mo } \\
\text { mo } \\
\text { mo }\end{array}$ & $\begin{array}{l}12 \\
50 \\
40 \\
50 \\
40 \\
24 \\
14 \\
30 \\
50 \\
08 \\
40 \\
08 \\
08 \\
\end{array}$ & $\begin{array}{l}2.83 \\
1.82 \\
3.18 \\
1.86 \\
2.50 \\
1.92 \\
2.69 \\
2.20 \\
1.90 \\
7.25 \\
1.90 \\
1.38 \\
1.38 \\
\end{array}$ & $\begin{array}{l}\frac{038}{082} \\
085 \\
048 \\
075 \\
075 \\
029 \\
077 \\
074 \\
000 \\
050 \\
063 \\
025\end{array}$ & $\begin{array}{l}1.58 \\
2.06 \\
2.18 \\
2.20 \\
1.30 \\
1.83 \\
1.36 \\
1.93 \\
1.78 \\
1.50 \\
2.18 \\
1.50 \\
1.25 \\
\end{array}$ & $\begin{array}{l}06 / 08=75 \\
53 / 64=83 \\
40 / 64=63 \\
26 / 44=59 \\
25 / 55=45 \\
25 / 42=60 \\
04 / 05=80 \\
30 / 47=64 \\
30 / 74=41 \\
0=0 \\
23 / 39=59 \\
05 / 07=71 \\
0=0\end{array}$ & $\begin{array}{l}07 \\
17 \\
15 \\
19 \\
11 \\
12 \\
04 \\
13 \\
17 \\
05 \\
13 \\
04 \\
06 \\
\end{array}$ \\
\hline $\begin{array}{l}s= \\
. d .=\end{array}$ & & & $\begin{array}{l}28.77 \\
17.20 \\
\end{array}$ & $\begin{array}{r}.52 \\
.52 \\
\end{array}$ & $\begin{array}{r}55.39 \\
26.32 \\
\end{array}$ & $\begin{array}{r}1.74 \\
.35 \\
\end{array}$ & $\begin{array}{l}59.08 \\
12.70 \\
\end{array}$ & $\begin{array}{l}11.00 \\
5.29 \\
\end{array}$ \\
\hline
\end{tabular}

Younger Subjects

\begin{tabular}{|c|c|c|c|c|c|c|c|c|}
\hline 101 & 24 & mo & 50 & 1.90 & 080 & 2.40 & $44 / 83=53$ & $\begin{array}{l}14 \\
09\end{array}$ \\
\hline 089 & $\begin{array}{l}24 \\
24\end{array}$ & mo & 16 & 1.81 & 088 & 1.88 & $16 / 27=57$ & $\begin{array}{l}09 \\
07\end{array}$ \\
\hline $\begin{array}{l}111 \\
087\end{array}$ & $\begin{array}{l}24 \\
24\end{array}$ & $\begin{array}{l}\text { mo } \\
\text { mo }\end{array}$ & $\begin{array}{l}18 \\
18\end{array}$ & $\begin{array}{l}5.51 \\
2.16\end{array}$ & $\frac{028}{028}$ & $\begin{array}{l}1.61 \\
1.33\end{array}$ & $\begin{array}{l}04 / 04=100 \\
04 / 06=67\end{array}$ & $\begin{array}{l}07 \\
08\end{array}$ \\
\hline 114 & 24 & mo & 07 & 8.00 & 014 & 1.43 & $02 / 02=100$ & 03 \\
\hline 093 & 24 & mo & 11 & 2.91 & 027 & 1.64 & $04 / 08=50$ & 04 \\
\hline 007 & 23 & mo & 50 & 1.98 & $\overline{012}$ & 2.18 & $04 / 09=44$ & 11 \\
\hline 142 & 22 & mo & 24 & 3.13 & $\overline{075}$ & 1.83 & $14 / 31=45$ & 07 \\
\hline 107 & 21 & mo & 02 & 8.00 & $\underline{000}$ & 1.00 & $0=0$ & 02 \\
\hline 109 & 21 & mo & 08 & 4.29 & $\underline{025}$ & 1.38 & $01 / 03=33$ & 05 \\
\hline 051 & 20 & mo & 28 & 1.14 & $\overline{014}$ & 1.89 & $03 / 05=60$ & 11 \\
\hline 057 & 20 & mo & 21 & 1.29 & $\overline{062}$ & 1.57 & $08 / 20=40$ & 07 \\
\hline 086 & 19 & mo & 21 & 2.24 & 057 & 1.81 & $10 / 16=63$ & 09 \\
\hline 098 & 19 & mo & 03 & 1.67 & $\underline{067}$ & 1.33 & $01 / 04=25$ & 01 \\
\hline 084 & 18 & mo & 07 & 12.14 & $\overline{000}$ & 1.00 & $0=0$ & 03 \\
\hline $\begin{array}{l}= \\
. d .=\end{array}$ & 21. & $\begin{array}{l}.80 \\
.21\end{array}$ & $\begin{array}{l}18.93 \\
14.80\end{array}$ & $\begin{array}{l}3.88 \\
3.20\end{array}$ & $\begin{array}{l}38.47 \\
29.93\end{array}$ & $\begin{array}{r}1.62 \\
.39\end{array}$ & $\begin{array}{r}51.58 \\
9.07\end{array}$ & $\begin{array}{l}6.73 \\
3.73\end{array}$ \\
\hline
\end{tabular}

MEANS AND STANDARD DEVIATIONS FOR THE LATE TALKER GROUP

Subj. Age \#Utter-Repeti- $\%$ Mean- SSL $\%$ correct \# true No. ances tions ingful consonants cons.

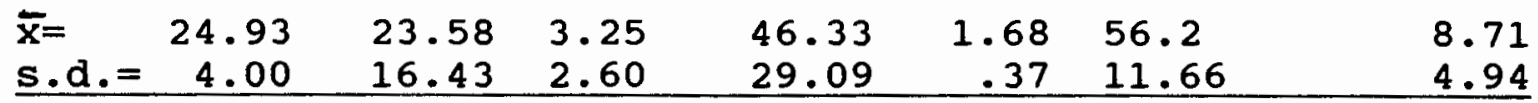


Key to chart

Age: Subject age, in months.

\# Utterances: Number of words or word-like utterances transcribed, up to 50 utterances or 10 minutes, whichever came first.

Repetitions: Average number of repetitions of each utterance by the subject.

\%eaningful: Percent of utterances in which the transcriber could identify an adult target word.

SSL: Sentence Structure Level.

$\%$ correct consonants: Percent of correct consonants : number of correctly produced consonants per number of consonants glossed.

\# true consonants: Number of different consonant types 